\title{
Insulating to Metallic behaviour in the Cation Ordered Perovskites \\ $\mathrm{Ba}_{2} \mathrm{Nd}_{1-x} \mathrm{Fe}_{x} \mathrm{MoO}_{6}$
}

Fiona C. Coomer, ${ }^{a}{ }^{\dagger}$ Serena A. Corr, ${ }^{b}$ Edmund J. Cussen*a

a WestCHEM, Department of Pure and Applied Chemistry, The University of Strathclyde, Thomas Graham Building, 295 Cathedral Street, Glasgow, G1 1XL, UK

b School of Chemistry, University of Glasgow, Glasgow G12 8QQ, UK

${ }^{\dagger}$ FCC Present address: ISIS Pulsed Neutron and Muon Source, STFC Rutherford Appleton Laboratory, Harwell Science and Innovation Campus, Didcot, Oxfordshire OX11 OQX, UK. *corresponding author: edmund.cussen@strath.ac.uk 


\section{Abstract}

The series of cation ordered double perovskites $\mathrm{Ba}_{2} \mathrm{Nd}_{1-\mathrm{x}} \mathrm{Fe}_{x} \mathrm{MoO}_{6}$ undergo a compositionallydriven transition from localised to delocalised electronic behaviour, as exhibited in the end members $\mathrm{Ba}_{2} \mathrm{NdMoO}_{6}$ and $\mathrm{Ba}_{2} \mathrm{FeMoO}_{6}$ respectively. Rietveld structural analyses against neutron diffraction data indicate that all compounds are stoichiometric in oxygen and show replacement of $\mathrm{Nd}^{3+}$ with $\mathrm{Fe}^{3+}$ on the larger of the two octahedral sites in the cation-ordered structure. A tetragonal distortion persists up to $\mathrm{x}=0.25$ and $\mathrm{Ba}_{2} \mathrm{Nd}_{0.9} \mathrm{Fe}_{0.1} \mathrm{MoO}_{6}$ shows freezing of magnetic moments at $5 \mathrm{~K}$. Neutron scattering indicates an absence of long range magnetic ordering suggesting the formation of a spin glass phase below this temperature. $\mathrm{Ba}_{2} \mathrm{Nd}_{0.75} \mathrm{Fe}_{0.25} \mathrm{MoO}_{6}$ shows high electrical resistivity with a temperature dependence indicative of fully localised electronic behaviour. Despite the $\mathrm{Fe}^{3+}$ occupation (0.25) being above the percolation limit $(0.195)$ for the face centred cubic lattice, this compound shows no magnetic ordering at $2 \mathrm{~K}$.

Compositions in the range $0.30 \leq x \leq 0.85$ give a mixture of two perovskite phases with lattice parameters of $c a .8 .4$ and $8.1 \AA$. The single phase compositions $\mathrm{Ba}_{2} \mathrm{Nd}_{0.10} \mathrm{Fe}_{0.90} \mathrm{MoO}_{6}$ and $\mathrm{Ba}_{2} \mathrm{Nd}_{0.05} \mathrm{Fe}_{0.95} \mathrm{MoO}_{6}$ form face centred cubic structures with long range magnetic ordering of the $\mathrm{Fe}^{3+}$ moments below ferrimagnetic ordering transitions of 270 and $285 \mathrm{~K}$ respectively. Neutron diffraction shows almost complete parallel alignment of the $\mathrm{Fe}^{3+}$ moments and, combined with conductivity measurements showing delocalised electronic behaviour in $\mathrm{Ba}_{2} \mathrm{Nd}_{0.10} \mathrm{Fe}_{0.90} \mathrm{MoO}_{6}$, indicate ferrimagnetic ordering of $\mathrm{Fe}^{3+}$ and delocalised $\mathrm{Mo}^{5+}$. 


\section{Introduction}

The perovskite structure is widely studied as it permits a diverse range of compositions and electronic behaviours. This is facilitated by a large range of available distortion modes giving a unique susceptibility for structural manipulation. These distortions can be understood by consideration of the ionic radii, and partial cation substitution can be used to vary the mean radii and so adjust the magnitude and symmetry of the distortions. ${ }^{1}$ In compounds containing a mixture of cations on the octahedral sites of the structure, the possibility of ordering of these cations brings an additional parameter to control the structure and guide the properties. ${ }^{2}$ Where the cations have similar properties then entropic considerations lead to the formation of a solid solution where the octahedrally-coordinated cations are distributed randomly on the crystallographic sites of the perovskite structure. The properties of these compounds may be described by considering the average structure, e.g. by using mean field assumptions, or other effects such as percolation may become critical in determining their properties. In general, properties of such cation-disordered materials can be approximated as modifications of the endmembers.

Cation ordering can lead to properties that are wholly different from the end members. This ordering arises when the alternative disordered arrangement of cations would lead to occasional clustering of like cations and so destabilise the structure. The disordered arrangement is highly unfavourable where the cations show a large difference in either or both their size and charge. If the octahedrally coordinated cations exhibit a large difference in cation radius then disorder would allow clusters of small, or clusters of large, cations to exist and so strain the lattice locally. Similarly, a large variation in cation charge would lead to unacceptable aggregation of positive or negative charge in the lattice, where clusters of high or low valence cations occupy the octahedra. The introduction of cation ordering in these so-called double perovskites can show emergent behaviour arising from the properties of the individual octahedral cations, combined with the effect of the ordering arrangement as well as any structural distortion. ${ }^{2}$

An example of this is given by comparing the behaviour of $\mathrm{Mo}^{5+}$ in the bronze phases, such as $\mathrm{Na}_{x} \mathrm{MoO}_{3}{ }^{3}$ with the cation ordered phases such as $\mathrm{Ba}_{2} \mathrm{LnMoO}_{6}{ }^{4}$ Both contain $\mathrm{MoO}_{6}$ octahedra. In the former the high concentration of $\mathrm{Mo}^{5+}$ in the lattice allows the formation of a delocalised electronic system, whereas in the latter the single electron of $\mathrm{Mo}^{5+}$ is localised on the molybdenum cation. Thus the properties of these materials differ greatly. In the series of 
$\mathrm{Ba}_{2} \mathrm{LnMoO}_{6}$ perovskites the size and charge difference between the lanthanide $\mathrm{Ln}^{3+}$ and $\mathrm{Mo}^{5+}$ cations gives rise to a rock salt type ordering shown in Figure 1.

There is a growing interest in the behaviour of $d^{1}$ cations $s^{5-11}$ in these octahedral sites within the perovskite structure. We and other groups have shown that structural distortions can by driven by the Jahn Teller instability of the triply degenerate state, $\mathrm{t}_{2 \mathrm{~g}}{ }^{1}$, in the octahedral ligand field. ${ }^{4,12-17}$ In addition to local electronic effects, magnetic frustration of the antiferromagnetic interaction between localised electron spins can arise due to the geometry of the face centred cubic, $f c c$, lattice. The neighbouring ions in an $f c c$ lattice are arranged on the vertices of an equilateral triangle. Consequently it is not possible for the moments on these neighbouring ions to adopt any arrangement that satisfies the antiparallel configuration favoured by antiferromagnetic coupling. The $f c c$ lattice is attracting growing attention as a source of frustration to examine weak interatomic interactions ${ }^{18}$ and the effect of spin multiplicity. ${ }^{5,19-20}$ In the case of $\mathrm{Ba}_{2} \mathrm{YMoO}_{6}$ and $\mathrm{Ba}_{2} \mathrm{LuMoO}_{6}$ this leads to the formation of a valence bond glass phase.

Cation ordered perovskites can also show delocalised electronic properties as is the case ${ }^{21}$ for $\mathrm{Ba}_{2} \mathrm{FeMoO}_{6}$ and related phases. ${ }^{22-23}$ Here the presence of partially occupied d-orbitals on both octahedrally coordinated cations allowed strongly electronic interactions between the magnetic centres. This material orders ferrimagnetically below $340 \mathrm{~K}$ giving rise to a net magnetisation due to the antiparallel alignment of $\mathrm{Fe}^{3+}\left(\mathrm{d}^{5}\right)$ and $\mathrm{Mo}^{5+}\left(\mathrm{d}^{1}\right)$. Due to the partial delocalisation of the $\mathrm{Mo}^{5+}$ electron, this gives rise to a spin polarised metallic conductivity and intragrain magnetoresistive behaviour. ${ }^{21,24-25}$ The magnetoresistance is an extrinsic effect that arises from the easier passage of electrons through the material due to the magnetic alignment caused by the application of an external magnetic field.

The electronically localised compounds $\mathrm{Ba}_{2} \mathrm{NdMoO}_{6}$ and $\mathrm{Ba}_{2} \mathrm{SmMoO}_{6}$ both show structural distortions driven by the instability of the $t_{2 g}{ }^{1} \mathrm{Mo}^{5+}$ cation in these compounds. ${ }^{14,}{ }^{16} \mathrm{Ba}_{2} \mathrm{NdMoO}_{6}$ has a tetragonally distorted double perovskite structure at room temperature. The distortion is driven by the mismatch between the $\mathrm{Ba}^{2+}$ cation and the oversized central interstices generated by the relatively large $\mathrm{NdO}_{6}$ octahedra. On cooling, a gradual distortion of the $\mathrm{MoO}_{6}$ octahedra occurs with a lengthening of the Mo-O bonds along the $z$ direction and contraction along the $x$ and $y$ directions At $190 \mathrm{~K}$ this distortion is sufficiently large that it leads to a reduction of crystallographic symmetry and $\mathrm{Ba}_{2} \mathrm{NdMoO}_{6}$ adopts the triclinic $I \overline{1}$ structure which persists down to $2 \mathrm{~K}^{14}$ This distortion partially lifts the degeneracy of $4 \mathrm{~d}^{1}$ configuration in an octahedral ligand 
field, and a similar distortion is observed in $\mathrm{Ba}_{2} \mathrm{SmMoO}_{6}$ albeit at significantly higher temperatures. $^{13}$

Partial replacement of $\mathrm{Nd}$ with $\mathrm{Y}^{3+}$ in the series $\mathrm{Ba}_{2} \mathrm{Nd}_{1-x} \mathrm{Y}_{x} \mathrm{MoO}_{6}$ introduces local strain into the lattice due to the variation in size between $\mathrm{Y}^{3+}$ and $\mathrm{Nd}^{3+}$. Structural studies at $2 \mathrm{~K}$ show that the Jahn Teller type of distortion can persist in the presence of cation doping; the introduction of $\mathrm{Y}^{3+}$ causes a gradual loss of this magnitude of the distortion which persists into a tetragonally distorted structure with the space group $14 / \mathrm{m}^{15}$

We aim to use this instability as a link between structural and electronic properties and so manipulate the transition between metallic and insulating behaviour observed in the semi-metallic double perovskite $\mathrm{Ba}_{2} \mathrm{FeMoO}_{6}{ }^{21}$ We have incorporated the structural instability of $\mathrm{Ba}_{2} \mathrm{NdMoO}_{6}$ with the semimetallic behaviour of $\mathrm{Ba}_{2} \mathrm{FeMoO}_{6}$ to examine the compositionally-driven transition from localised to delocalised electronic behaviour. Here we describe our examination of the compositions $\mathrm{Ba}_{2} \mathrm{Nd}_{1-x} \mathrm{Fe}_{x} \mathrm{MoO}_{6}$ where we identify compositional phase limits in this multiphase system. We observe the effect of doping $\mathrm{Fe}^{3+}$ into the localised $\mathrm{Ba}_{2} \mathrm{NdMoO}_{6}$ system as well as the effect of $\mathrm{Nd}^{3+}$ in the partially delocalised $\mathrm{Ba}_{2} \mathrm{FeMoO}_{6}$ phase.

\section{Experimental}

Polycrystalline samples were prepared by heating stoichiometric quantities of $\mathrm{BaCO}_{3}, \mathrm{Nd}_{2} \mathrm{O}_{3}, \mathrm{Fe}_{2} \mathrm{O}_{3}$ and $\mathrm{MoO}_{3}$ at temperatures up to $1250{ }^{\circ} \mathrm{C}$ in a flowing atmosphere of $5 \% \mathrm{H}_{2}$ in $\mathrm{N}_{2}$. After initially grinding the mixture of reagents these were heating to $800^{\circ} \mathrm{C}$ at $1^{\circ} \mathrm{C} \mathrm{min}-1$ in air in order to limit losses of volatile molybdenum oxide. The samples were weighed before and after heating to check that no significant mass loss occurred. The samples were then reground, pelleted and heated under reducing conditions for several days, with intermediate grinding and repelleting. Total heating times were up to six days at $1250^{\circ} \mathrm{C}$. The reaction mixtures were examined using a Panalytical $X^{\prime}$ Pert powder diffractometer operating with $\mathrm{Cu}$ Ka radiation and were judged to be 
complete when the pattern could be indexed as a single phase or when further heating caused no discernible change in the diffraction profile. The samples were cooled to room temperature over the course of several hours in the $5 \% \mathrm{H}_{2}$ atmosphere.

Neutron powder diffraction data were collected using the constant wavelength instrument D2B at the Institut Laue Langevin, Grenoble. The samples were contained in cylindrical vanadium cans and temperature was controlled using an orange cryostat. Structural analysis was performed using Rietveld refinement as configured in the GSAS programs.

Magnetic measurements were conducted by using a Quantum Design MPMS SQUID magnetometer to measure ca. $50 \mathrm{mg}$ of sample contained in a gelatine capsule. Data were collected in an applied field after cooling in either the measuring field or in zero applied field and were not corrected for diamagnetism. Susceptibility data were fitted using the Curie Weiss law in the temperature range 150 to $300 \mathrm{~K}$.

Electrical transport measurements were carried out using the four-probe d.c. method on a sintered bar of sample with dimensions $2 \times 4 \times 9 \mathrm{~mm}$ using a Quantum Design PPMS system. Data collections were repeated in an applied longitudinal field. The zero field measurements were then reproduced after the field had been removed in order to check the repeatability and history dependence on the conductivity. 


\section{Results}

After multiple grinding and heating cycles the X-ray powder diffraction patterns collected from this series of compounds were invariant, indicating that no further reaction was occurring. From inspection of these diffraction patterns it was evident that there are three ranges in this series of compounds; single phase samples were obtained at each end of the compositional series and a two-phase region exists between them as shown in Figure 2. Multiple attempts were made to these convert two phase samples into single phases, with repeated synthesis, alterations of heating temperature and rapid cooling but in every case two-phase samples resulted. We will discuss the chemistry and magnetic properties of each of these three regimes in turn.

$\mathrm{Fe}$-doped $\mathrm{Ba}_{2} \mathrm{NdMoO}_{6}$

Compositions containing up to $\mathrm{x}=0.25$ in the series $\mathrm{Ba}_{2} \mathrm{Nd}_{1-x} \mathrm{Fe}_{x} \mathrm{MoO}_{6}$ could be indexed as single perovskite phases. For the smallest doping values, of $x=0.05$ and 0.10 , the $x$-ray diffraction profiles clearly exhibited a splitting of the peaks indicative of a metric tetragonal distortion. Examination of these two samples using neutron diffraction confirmed the tetragonal symmetry and provided a good agreement between the observed data and $14 / \mathrm{m}$ symmetry exhibited at room temperature by the $\mathrm{Ba}_{2} \mathrm{NdMoO}_{6}$ parent phase. Magnetic measurements on these compounds showed typical Curie Weiss behaviour and the data collected above $150 \mathrm{~K}$ were fitted to give values of $\mathrm{C}$ of $1.958(8) \mathrm{cm}^{3} \mathrm{~K} \mathrm{~mol}^{-1}$ and $\theta$ of $-53(1) \mathrm{K}$ for $\mathrm{Ba}_{2} \mathrm{Nd}_{0.95} \mathrm{Fe}_{0.05} \mathrm{MoO}_{6}$ and $\mathrm{C}$ of $1.98(2) \mathrm{cm}^{3} \mathrm{~K} \mathrm{~mol}^{-1}$ and $\theta$ of $-41(2) \mathrm{K}$ for $\mathrm{Ba}_{2} \mathrm{Nd}_{0.90} \mathrm{Fe}_{0.10} \mathrm{MoO}_{6}$. Both compounds showed magnetic transitions at low temperature where the field-cooled and zero field-cooled data diverged depending on the sample history. The neutron diffraction profile collected from $\mathrm{Ba}_{2} \mathrm{Nd}_{0.90} \mathrm{Fe}_{0.10} \mathrm{MoO}_{6}$ at $2 \mathrm{~K}$ is shown in Figure 3, and can be satisfactorily fitted using the same $14 / \mathrm{m}$ model as the room temperature data to give the parameters $R_{w p}=4.35, \chi^{2}=9.44$. There is no evidence of either a structural distortion or additional low angle Bragg peaks indicative of long range ordering of the magnetic moments in this material. The history dependence of the magnetisation below $5 \mathrm{~K}$ indicates that the magnetic moments are in a static arrangement, but the neutron diffraction profile shows that there is no long range magnetic ordering. Taken together, these two observations suggest the freezing of magnetic moments in a disordered manner, i.e. the formation of a spin glass occurs on cooling below $5 \mathrm{~K}$. 
Increased doping levels to compositions $x=0.20$ and 0.25 gave $x$-ray patterns that could be indexed using the face centred cubic symmetry of cation ordered perovskite, alongside additional peaks from a small amount, ca. 0.40(2) wt\%, of iron impurity. The neutron diffraction profiles collected at room temperature from both of these samples could be satisfactorily indexed using the $F m \overline{3} m$ space group. However, close inspection of the peak intensities arising from the expansion of the perovskite cell showed that these were underestimated using this model. These data are better described using the tetragonal distortion which gives a significantly better fit, $\mathrm{R}_{\mathrm{wp}}=$ $2.28, \chi^{2}=3.66$ for $\mathrm{Ba}_{2} \mathrm{Nd}_{0.80} \mathrm{Fe}_{0.20} \mathrm{MoO}_{6}$ and $\mathrm{R}_{\mathrm{wp}}=3.90, \chi^{2}=6.94$ for $\mathrm{Ba}_{2} \mathrm{Nd}_{0.75} \mathrm{Fe}_{0.25} \mathrm{MoO}_{6}$. The lattice parameters are similar to cubic and so there is minimal peak splitting in the data collected at room temperature as shown in Figure 3. The loss of symmetry is clearly manifested in the tilting of the metal oxide octahedra around the four-fold axis to give a $\mathrm{Nd}-\mathrm{O}(2)-\mathrm{Mo}$ angles of $169.93(12)$ and $171.5(2)^{\circ}$ for $x=0.20$ and 0.25 respectively.

Additional neutron diffraction data sets collected on cooling $\mathrm{Ba}_{2} \mathrm{Nd}_{0.75} \mathrm{Fe}_{0.25} \mathrm{MoO}_{6}$ showed that from $160 \mathrm{~K}$ to $2 \mathrm{~K}$ the diffraction profiles showed pronounced changes in peak shape and the profile at $2 \mathrm{~K}$ contains significant peak broadening which degrades the quality of the fit to give parameters $R_{w p}=5.14, \chi^{2}=12.07$. The temperature dependence of the lattice parameters and Mo-O bond lengths of $\mathrm{Ba}_{2} \mathrm{Nd}_{0.75} \mathrm{Fe}_{0.25} \mathrm{MoO}_{6}$ are shown in Figure 4 and show highly anisotropic behaviour with negative thermal expansion of the $c$ lattice parameter. There is no indication of magnetic ordering.

Conductivity measurements on a sample $\mathrm{Ba}_{2} \mathrm{Nd}_{0.75} \mathrm{Fe}_{0.25} \mathrm{MoO}_{6}$ show thermally activated conductivity with a large low temperature resistance that decreased on heating. As shown in Figure 5 , there is no field dependence to the resistance for this compound.

Two Phase Region, $0.3 \leq x \leq 0.85$

Increasing the Fe-content produced samples whose diffraction patterns were characteristic of a two phase mixture. Portions of the $x$-ray diffraction profiles are shown in Figure 6 and contain two peaks indicative of separate reflections arising from two double perovskite structures. The two sets of peaks in these patterns could be indexed using lattice parameters of $c a .8 .4$ and $8.1 \AA$ to represent two face centred phases. As the value of $x$ is increased, the relative intensity of the 
peaks at lower angle decreases indicating that the relative quantity of the larger perovskite phase is decreasing. For $\mathrm{Ba}_{2} \mathrm{Nd}_{0.15} \mathrm{Fe}_{0.85} \mathrm{MoO}_{6}$ there is an estimated $10 \%$ of the larger perovskite phase. This is entirely eliminated on further doping as shown by a single phase pattern obtained for $\mathrm{Ba}_{2} \mathrm{Nd}_{0.10} \mathrm{Fe}_{0.90} \mathrm{MoO}_{6}$.

Fe-rich $\mathrm{Ba}_{2} \mathrm{Nd}_{1-x} \mathrm{Fe}_{x} \mathrm{MoO}_{6} ; x \geq 0.90$

Two, single-phase compounds were prepared the Fe-rich end of this series; $\mathrm{Ba}_{2} \mathrm{Nd}_{0.10} \mathrm{Fe}_{0.90} \mathrm{MoO}_{6}$ and $\mathrm{Ba}_{2} \mathrm{Nd}_{0.05} \mathrm{Fe}_{0.95} \mathrm{MoO}_{6}$. Examination of the $\mathrm{X}$-ray diffraction profiles of both of these compounds indicated a single phase double perovskite had been formed with cubic symmetry. This assignment is confirmed for both compounds by neutron diffraction data collected at room temperature which could readily by fitted in space group with complete cation ordering of $\mathrm{Fe} / \mathrm{Nd}$ and $\mathrm{Mo}$ across the two sites in the structure. Additional neutron diffraction data were collected from $\mathrm{Ba}_{2} \mathrm{Nd}_{0.05} \mathrm{Fe}_{0.95} \mathrm{MoO}_{6}$ as the sample was cooled. The data collected from this material at $2 \mathrm{~K}$ contained additional intensity in several of the low angle reflections as shown in Figure 7.

The parent phase $\mathrm{Ba}_{2} \mathrm{FeMoO}_{6}$ contains magnetically ordered moments and so a long-range magnetically ordered structure was included in the refinement model for $\mathrm{Ba}_{2} \mathrm{Nd}_{0.05} \mathrm{Fe}_{0.95} \mathrm{MoO}_{6}$ in order to allow a magnetic contribution to the Bragg scattering. There is no evidence of peak splitting in the diffraction profile and le Bail fit to the profile gives a high level of agreement, indicating there is no departure from metric cubic symmetry. However, the magnetic ordering observed in $\mathrm{Ba}_{2} \mathrm{FeMoO}_{6}$ is incompatible with the space group symmetry. We could readily fit the neutron diffraction profile using a reduction to tetragonal symmetry, $14 / \mathrm{mmm}$, that allows the magnetic moments to order with magnetic symmetry Fmmm'. This approach has the advantage of providing compatible symmetry for both the nuclear and magnetic structures, but the disadvantage of using a space group of lower symmetry than is required to reproduce the nuclear crystallographic structure. We have elected to use an alternative modelling approach of using cubic symmetry for the nuclear crystal structure and a lower symmetry for the magnetic structure. This gives the same quality of fit as the application of Fmmm' magnetic symmetry.

The magnetic structure ${ }^{23}$ of $\mathrm{Ba}_{2} \mathrm{FeMoO}_{6}$ was used as a starting point for the magnetic refinement and the data collected from $\mathrm{Ba}_{2} \mathrm{Nd}_{0.05} \mathrm{Fe}_{0.95} \mathrm{MoO}_{6}$ at $2 \mathrm{~K}$ indicate an ordered moment of $4.33(6) \mu_{\mathrm{B}}$ per Fe atom aligned along the $z$ direction. The moment of the Mo site is aligned antiparallel to this page 9 
$-0.27(10) \mu_{\mathrm{B}}$. Trial refinements used to test the reliability of the moment on the Mo site indicated that this made no significant contribution to the agreement between the calculated profile and the observed magnetic scattering. Consequently, the moment on the Mo site was fixed to be zero and a single collinear moment on Fe was refined to give the quality of fit parameters $R_{w p}=8.65, \chi^{2}$ $=4.33$.

Additional data sets collected on heating the sample show that the magnetic contribution to the Bragg scattering is present at temperatures up to $200 \mathrm{~K}$. Trial refinements against the room temperature data showed that these are unable to determine an ordered magnetic moment of less than $\approx 0.5 \mu_{\mathrm{B}}$ with any reliability. Allowing refinement of a magnetic moment against the room temperature data led to a spurious value of $0.6(3) \mu_{B}$, which provides an indication of the sensitivity of these refinements.

Bulk magnetic measurements on both of these samples showed a large spontaneous magnetisation occurring at 270 and $285 \mathrm{~K}$ for $\mathrm{Ba}_{2} \mathrm{Nd}_{0.10} \mathrm{Fe}_{0.90} \mathrm{MoO}_{6}$ and $\mathrm{Ba}_{2} \mathrm{Nd}_{0.05} \mathrm{Fe}_{0.95} \mathrm{MoO}_{6}$ respectively as shown in Figures 8 and 9. Isothermal magnetisation measurement of $\mathrm{Ba}_{2} \mathrm{Nd}_{0.05} \mathrm{Fe}_{0.95} \mathrm{MoO}_{6}$ at $1.5 \mathrm{~K}$ shows a readily saturated magnetisation of $3.4 \mu_{\mathrm{B}}$ per formula unit with remnant magnetisation, $M_{r}$ of $0.1 \mu_{B}$ and coercive field, $H_{c}$ of $-20 \mathrm{G}$ indicative of almost zero hysteresis.

Electrical transport measurements on $\mathrm{Ba}_{2} \mathrm{Nd}_{0.10} \mathrm{Fe}_{0.90} \mathrm{MoO}_{6}$ show a low resistivity, which increases slowly with temperature as shown in Figure 8. Measurements in zero field show a considerable dependence on sample history above $245 \mathrm{~K}$, with the pristine material showing a resistivity of 120 $\Omega \mathrm{cm}$ which is reduced to $45 \Omega \mathrm{cm}$ on warming. This measurement was repeated and showed that the irregular behaviour above the transition temperature persisted in zero field. The application of a magnetic field of $1 \mathrm{~T}$ causes a reduction in the resistivity of the sample of around $20 \%$ below $250 \mathrm{~K}$. 


\section{Discussion}

$\mathrm{Ba}_{2} \mathrm{NdMoO}_{6}$ and $\mathrm{Ba}_{2} \mathrm{FeMoO}_{6}$ adopt closely related structures, but our study of the compositional series $\mathrm{Ba}_{2} \mathrm{Nd}_{1-x} \mathrm{Fe}_{x} \mathrm{MoO}_{6}$ shows that there is a solubility gap between these two phases for values of $x$ between 0.30 and 0.85 . To understand the origins of this gap we will look firstly at the properties at either end of the series where single phase materials were prepared and their structure and electronic behaviours have been characterised in detail.

The chemical substitution which we have undertaken here involves a replacement of $\mathrm{Nd}^{3+}$ with iron cations. The synthetic conditions have been chosen to stabilise the $\mathrm{Fe}^{3+}$ oxidation state in these materials but it should of course be considered that the perovskite structure is capable of supporting vacant sites on both anion and cation sublattices and there is scope for variable oxidation states from molybdenum where $\mathrm{Mo}^{6+}$ is known to form in similar compounds. ${ }^{26}$ The structures of these compounds have been mainly analysed using neutron powder diffraction. In all cases multiple refinements were undertaken to test these materials for oxide non-stoichiometry and indications of cation disorder i.e. mixing of the iron cations onto the Mo site rather than the anticipated $\mathrm{Nd}$ site. For all of these refinements the compounds were found to be stoichiometric in oxygen. We found no evidence of mixing of iron onto the molybdenum sites in the structure though mixing of the level of $1-2 \%$ is beyond the sensitivity of these diffraction data. Thus the following discussion is based on compounds that are fully stoichiometric in oxide and have achieved the target cation stoichiometries and contain $\mathrm{Nd}^{3+}, \mathrm{Fe}^{3+}$ and $\mathrm{Mo}^{5+}$.

Localised Electronic Behaviour in Nd-rich phases up to $\mathrm{Ba}_{2} \mathrm{Nd}_{0.75} \mathrm{Fe}_{0.25} \mathrm{MoO}_{6}$

The tetragonal structure of $\mathrm{Ba}_{2} \mathrm{NdMoO}_{6}$ has been modified by the introduction of $\mathrm{Fe}^{3+}$ onto the lattice in place of $\mathrm{Nd}^{3+}$ for the compositions up to and including $\mathrm{Ba}_{2} \mathrm{Nd}_{0.75} \mathrm{Fe}_{0.25} \mathrm{MoO}_{6}$. For the modest quantity of $10 \%$ iron we see some dramatic changes in both the structural chemistry and magnetic properties of $\mathrm{Ba}_{2} \mathrm{Nd}_{0.90} \mathrm{Fe}_{0.10} \mathrm{MoO}_{6}$. At $2 \mathrm{~K}$ this compound shows largely regular transition metal octahedra in contrast to the distortion observed in $\mathrm{Ba}_{2} \mathrm{NdMoO}_{6}$. This subtle change in structure has significant consequences for the magnetic coupling between the $\mathrm{Mo}^{5+}$ and $\mathrm{Nd}^{3+}$. The splitting of the $t_{2 \mathrm{~g}}$ manifold in $\mathrm{Ba}_{2} \mathrm{NdMoO}_{6}$ leads to stabilisation of ferromagnetic coupling along the $z$ direction due to the depopulation of the $4 p_{z}$ orbital. This can be contrasted with $\mathrm{Ba}_{2} \mathrm{SmMoO}_{6}$ and $\mathrm{Ba}_{2} \mathrm{EuMoO}_{6}$ which show much higher Neel temperatures due to the dominant Ln-O-O-Ln interaction. There are multiple and often conflicting superexchange interactions in the fully cation page 11 
ordered examples. These conflicts arise from the various correlation and delocalisation superexchange mechanisms for coupling in these phases. The subtleties of the structural distortion are key, as in the splitting of the $\mathrm{t}_{2 \mathrm{~g}}$ manifold in $\mathrm{Ba}_{2} \mathrm{NdMoO}_{6}$ introducing anisotropic coupling in the long range antiferromagnetic structure. A thorough discussion of the interactions between the $\mathrm{Mo}^{5+} 4 \mathrm{~d}^{1}$ and $\mathrm{Nd}^{3+} 4 \mathrm{f}^{3}$ electrons ${ }^{4}$ and comparison with other lanthanides ${ }^{13}$ has been provided in studies of $\mathrm{Ba}_{2} \mathrm{NdMoO}_{6}, \mathrm{Ba}_{2} \mathrm{SmMoO}_{6}$ and $\mathrm{Ba}_{2} \mathrm{ErMoO}_{6}{ }^{27}$

We can also contrast the magnetic behaviours of these fully cation-ordered materials with the end members; whereas $\mathrm{Ba}_{2} \mathrm{NdMoO}_{6}$ shows clear antiferromagnetic ordering of both the molybdenum and neodymium moments below the Néel temperature of $15 \mathrm{~K}, \mathrm{Ba}_{2} \mathrm{Nd}_{0.90} \mathrm{Fe}_{0.10} \mathrm{MoO}_{6}$ does not contain any indication of long-range magnetic ordering in the neutron diffraction profile at $2 \mathrm{~K}$. The magnetic susceptibility of this compound follows Curie-Weiss behaviour at high-temperature with a Weiss constant of $-41(2) \mathrm{K}$ indicative of moderate antiferromagnetic coupling. The history dependence of the magnetisation at the lowest temperatures indicates a partial freezing of spins below a magnetic transition at $5 \mathrm{~K}$. Given the absence of magnetic Bragg scattering in the neutron diffraction pattern at $2 \mathrm{~K}$, we conclude that this magnetic transition is associated with the change from a dynamic paramagnetic state to a static, disordered state, i.e. a spin glass forms below $T_{g} \approx$ $5 K$.

The presence of $\mathrm{Fe} / \mathrm{Nd}$ occupational disorder adds considerable complexity to the magnetic interactions and the absence of long range magnetic order in the electronically-localised phases do not give an insight into the dominant local exchange mechanisms in these compositions. It is likely that the conflicting interactions, combined with the $\mathrm{Fe} / \mathrm{Nd}$ disorder frustrate the formation of a long range magnetically ordered state. This frustration is also reflected in the lowered transition temperature compared to the $15 \mathrm{~K}$ seen in $\mathrm{Ba}_{2} \mathrm{NdMoO}_{6}$.

Compounds have also been prepared where the iron doping has been increased above the percolation limit for face centred cubic lattice, $p_{c}=0.195$. This concentration, of $19.5 \% \mathrm{Fe}$ onto the site, is the critical value above which a continuous three-dimensionally linked network of Fe-O-Mo-O-Fe exists throughout the $f c c$ structure. ${ }^{28}$ Such a connectivity is achieved for the compositions $\mathrm{Ba}_{2} \mathrm{Nd}_{0.80} \mathrm{Fe}_{0.20} \mathrm{MoO}_{6}$ and $\mathrm{Ba}_{2} \mathrm{Nd}_{0.75} \mathrm{Fe}_{0.25} \mathrm{MoO}_{6}$. It could therefore be anticipated that these materials could generate the delocalised ferrimagnetic state observed for $\mathrm{Ba}_{2} \mathrm{FeMoO}_{6}$ as a minority portion of the material with conductivity through the lattice, and with additional isolated 
regions of where the Fe-O-Mo-O-Fe connections are disconnected from the continuous backbone.

The presence of metallic iron impurity in the $x=0.20$ and $x=0.25$ compositions dominates the magnetisation, but the low temperature neutron diffraction data collected from these compounds show the absence of long range magnetic order in the perovskite. The presence of metallic impurity also must be considered when discussing the transport properties. If the impurity formed a continuous path through the sample then it would dominate the measurement and indicate a low resistivity. However the resistivity of $\mathrm{Ba}_{2} \mathrm{Nd}_{0.75} \mathrm{Fe}_{0.25} \mathrm{MoO}_{6}$ unambiguously shows a highly localised electronic system with thermally activated conductivity. Thus even at this relatively high doping level it appears that the electrons of the $\mathrm{Mo}^{5+}, \mathrm{d}^{1}$, cation remain fully localised. The presence of the metallic impurity could only reduce the observed resistance and so the localised behaviour in this sample of $\mathrm{Ba}_{2} \mathrm{Nd}_{0.75} \mathrm{Fe}_{0.25} \mathrm{MoO}_{6}$ must reflect the properties of the majority double perovskite phase; there is no delocalised semi-metallic backbone running through the perovskite $\mathrm{Ba}_{2} \mathrm{Nd}_{0.75} \mathrm{Fe}_{0.25} \mathrm{MoO}_{6}$.

The localisation of these electrons is also significant to the structure of $\mathrm{Ba}_{2} \mathrm{Nd}_{0.75} \mathrm{Fe}_{0.25} \mathrm{MoO}_{6}$. On cooling below $150 \mathrm{~K}$ this material undergoes a considerable distortion with significant variation of the lattice paramaters from the approximately metric cubic symmetry they display for $\mathrm{T}>150 \mathrm{~K}$. There is a considerable distortion of the $\mathrm{MoO}_{6}$ octahedra with 2 short and 4 longer bonds indicating a $z$-in type of distortion. This completely lifts the degeneracy of the $\mathrm{t}_{2 \mathrm{~g}}{ }^{1}$ electron in this distorted octahedral ligand field. Orbital ordering of $\mathrm{Mo}^{5+}$ has driven lattice distortions in related compounds, although it is unclear why it is manifested here in $\mathrm{Ba}_{2} \mathrm{Nd}_{0.75} \mathrm{Fe}_{0.25} \mathrm{MoO}_{6}$ but not at the same level in $\mathrm{Ba}_{2} \mathrm{Nd}_{0.90} \mathrm{Fe}_{0.10} \mathrm{MoO}_{6}$ which shows a much more modest distortion with Mo-O distances of $4 \times 1.950(2) \AA$ and $2 \times 1.986(2) \AA$ at $2 \mathrm{~K}$. The much larger distortion and the associated peak broadening observed in $\mathrm{Ba}_{2} \mathrm{Nd}_{0.75} \mathrm{Fe}_{0.25} \mathrm{MoO}_{6}$ have stronger parallels with the behaviour of $\mathrm{Ba}_{2} \mathrm{GdMoO}_{6}{ }^{16}$ This compound undergoes a cubic to triclinic distortion in a ferroelastic transition that strains the lattice. Although we cannot identify any change in lattice symmetry on cooling $\mathrm{Ba}_{2} \mathrm{Nd}_{0.75} \mathrm{Fe}_{0.25} \mathrm{MoO}_{6}$ the assymetric peak broadening is indicative of considerable spontaneous strain in the lattice as the sample is cooled below $160 \mathrm{~K}$. It may be that the large increase in the metric distortion of the lattice evident in the lattice parameters is unable to propagate readily through the sample and this is leading the unresolved peak broadening. 
Magnetic measurements on the $x=0.20$ and 0.25 compositions show significant magnetisation at room temperature as well as a weak history dependent magnetic transition around $170 \mathrm{~K}$ and a Curie Weiss tail at low temperature. The neutron diffraction profiles of these two compositions both indicated the presence of a small amount of body centred cubic $\alpha$-Fe in the sample. This ferromagnetic impurity dominates the magnetic measurements of these samples and preclude further useful interpretation of these magnetisation data.

\section{Delocalisation of Electrons in Fe-rich $\mathrm{Ba}_{2} \mathrm{Nd}_{0.10} \mathrm{Fe}_{0.90} \mathrm{MoO}_{6}$}

For the iron-rich end of the series, single-phase, double perovskites have been formed for the $x=$ 0.10 and 0.05 compositions. Electrical transport measurements indicate a dramatic change from the $\mathrm{Nd}$-rich materials at the other end of the compositional series. $\mathrm{Ba}_{2} \mathrm{Nd}_{0.10} \mathrm{Fe}_{0.90} \mathrm{MoO}_{6}$ is a highly conducting material which shows an increasing resistance with temperature indicative of scattering of charge carriers from lattice phonons. Multiple resistivity measurements showed some degree of drift in the value but in every case the resistivity was reduced by approximately $20 \%$ by the application of a magnetic field. Similar magnetoresistance effects have been extensively studied in $\mathrm{Ba}_{2} \mathrm{FeMoO}_{6}$ and $\mathrm{Sr}_{2} \mathrm{FeMoO}_{6}$ and these arise from the minimisation of intragrain barriers to charge transport by increasing the alignment between magnetic domains by application of a magnetic field. ${ }^{21,24}$ The large change in conductivity observed at the magnetic transition temperature of $250 \mathrm{~K}$ arises from the alignment of the magnetic domains and thus is an effect of the magnetic microstructure. Thus the transport properties of $\mathrm{Ba}_{2} \mathrm{Nd}_{0.10} \mathrm{Fe}_{0.90} \mathrm{MoO}_{6}$ appear similar to $\mathrm{Ba}_{2} \mathrm{FeMoO}_{6}$ with no special enhancement arising from the introduction of $\mathrm{Nd}^{3+}$ into the lattice. The resistivity of this material in zero applied field shows a curious history dependence whereby the initial resistivity value is much higher than expected on cooling to $140 \mathrm{~K}$, but measuring data again on warming shows significant reduction in the resistivity. The divergences between these data occurs in $250 \mathrm{~K}$. This strongly suggests that it is in some way linked to the manipulation of microstructure by the magnetic transition which we see around this temperature. A precise description of the origin of these changes lies beyond the scope of the current paper but we include the data here for the sake of completeness and to note this unusual observation.

These compounds adopt the face centred cubic structure and so are isostructural with the $\mathrm{Ba}_{2} \mathrm{Fe}-$ $\mathrm{MoO}_{6}$ parent. Crystallographic cubic symmetry is indicated in the neutron diffraction data 
collected on cooling $\mathrm{Ba}_{2} \mathrm{Nd}_{0.05} \mathrm{Fe}_{0.95} \mathrm{MoO}_{6}$ to $2 \mathrm{~K}$. This neutron diffraction profile indicates longrange magnetic ordering is present, however the constraints of the space group do not allow the identification of the unique vector for the ordering of the magnetic moments. The observed magnetic Bragg scattering is similar to that observed ${ }^{23}$ in the $\mathrm{Ba}_{2} \mathrm{FeMoO}_{6}$ end member and can be modelled with a similar ferromagnetic alignment of moments on the iron/neodymium site. Refinement of an antiparallel moment on the $\mathrm{Mo}^{5+}$ cations indicates a very low value around the detection limit for neutron diffraction data. The long-range ferromagnetically ordered moments observed on the $\mathrm{Fe} / \mathrm{Nd}$ site can be described as 4.33(6) per $\mathrm{Fe}^{3+}$ cation if the $\mathrm{Nd}^{3+}$ cations are assumed to make no contribution to the long range ordering. Such an assignment of disordered $\mathrm{Nd}^{3+}$ moments cannot be directly observed or supported via bulk magnetic measurements as these are dominated by the ferromagnetic alignment of the $\mathrm{Fe}^{3+}$ cations. The coupling of $\mathrm{Nd}^{3+}$ would be mediated by transfer of the delocalised $\mathrm{Mo}^{5+}$ electron into the empty $5 \mathrm{~d}$ orbitals and Hund's rule coupling of the $\mathrm{Nd}^{3+} 4 f^{3},{ }^{4} \mathrm{I}_{9 / 2}$ state with this electron would lead to the $\mathrm{Nd}^{3+}$ moment of $3.62 \mu_{\mathrm{B}}$ being aligned parallel to the delocalised electron and antiparallel to the $\mathrm{Fe}^{3+}$ moments. Thus ordering of the Nd would lead to partial cancellation of the Fe moment. This would give a reduction in the apparent ordered moment on this site from $4.5 \mu_{\mathrm{B}}$ (full ordering of $\mathrm{gS}=5 \mu_{\mathrm{B}}$ for 90 \% Fe occupancy) to $4.14 \mu_{B}\left(4.5 \mu_{B}-0.10 \times 3.62 \mu_{B}\right)$. The observed ordered moment of $4.33(6)$ per $\mathrm{Fe}^{3+}$ is somewhat reduced from the value of $\mathrm{gS}=5 \mu_{\mathrm{B}}$ that may be anticipated for $\mathrm{Fe}^{3+}$, but it is in good agreement with the value expected ${ }^{29}$ for a fully ordered antiferromagnetic oxide of $\mathrm{Fe}^{3+}$ and is slightly larger than the value of $4.06 \mu_{\mathrm{B}}$ per $\mathrm{Fe}^{3+}$ observed in $\mathrm{Ba}_{2} \mathrm{FeMoO}_{6}{ }^{23}$ This strongly suggests that the $\mathrm{Nd}^{3+}$ cations remain disordered at $2 \mathrm{~K}$, within a matrix of ferromagnetically ordered Fe moments.

The parent phase $\mathrm{Ba}_{2} \mathrm{FeMoO}_{6}$ magnetically orders ${ }^{21}$ below $340 \mathrm{~K}$ and the reduction in the ordering temperature caused by the introduction of $\mathrm{Nd}^{3+}$ is dramatic. Both the $\mathrm{x}=0.05$ and $\mathrm{x}=0.10$ compounds show a large spontaneous increase in magnetisation, at 285 and $270 \mathrm{~K}$ respectively. Comparable doping with $\mathrm{Mn}$ or $\mathrm{Zn}$ in $\mathrm{Ba}_{2} \mathrm{Fe}_{1-\mathrm{x}} \mathrm{M}_{\mathrm{x}} \mathrm{MoO}_{6}$ also leads to a reduction in the magnetic transition temperature, but required 30 or $50 \%$ substitution to achieve a similar temperature change. ${ }^{22}$ The lattice parameter of $\mathrm{Ba}_{2} \mathrm{Nd}_{0.10} \mathrm{Fe}_{0.90} \mathrm{MoO}_{6}$ is $8.1157(4) \AA$ which is significantly larger than compositions with similar magnetic ordering temperatures; $8.113 \AA$ for $\mathrm{Ba}_{2} \mathrm{Fe}_{0.7} \mathrm{Mn}_{0.3} \mathrm{MoO}_{6}$ and $8.084 \AA$ for $\mathrm{Ba}_{2} \mathrm{Fe}_{0.5} \mathrm{Zn}_{0.5} \mathrm{MoO}_{6}$. This suggests that the reduction in the ordering temperature is being dominated by the expansion of the lattice, and associated reduction in superexchange 
orbital overlap rather than the reduction in magnetic interactions arising from dilution of the Fe sublattice.

Phase Separation in the Two Phase Region; $0.3 \leq x \leq 0.85$

All compositions studied here crystallise with the basic same cation-ordered double perovskites structure. Given these similarities it could be expected that solid solution would readily be obtained. However, despite multiple attempted syntheses to facilitate the formation of single phases throughput the compositional series, we observe a two-phase region between the compositions $\mathrm{Ba}_{2} \mathrm{Nd}_{0.70} \mathrm{Fe}_{0.30} \mathrm{MoO}_{6}$ and $\mathrm{Ba}_{2} \mathrm{Nd}_{0.10} \mathrm{Fe}_{0.90} \mathrm{M} \mathrm{oO}_{6}$. Although the end members adopt the same basic structure type it should be noted that the considerable difference in their cell volumes indicate that these structures are significantly different.

The introduction of Fe into the tetragonally distorted phase $\mathrm{Ba}_{2} \mathrm{NdMoO}_{6}$ reduces the size of the metric distortion but there is significant local strain associated with replacing the larger $\mathrm{Nd}^{3+}$ cation with $\mathrm{Fe}^{3+}$. At this end of the series up to $25 \%$ substitution is tolerated. It is interesting to note the asymmetry in the solubility limits with only $10 \%$ substitution possible into $\mathrm{Ba}_{2} \mathrm{FeMoO}_{6}$. The introduction of $\mathrm{Nd}$ into $\mathrm{Ba}_{2} \mathrm{FeMoO}_{6}$ will introduce local distortions that will tend to localise the $\mathrm{Mo}^{5+} 4 \mathrm{~d}^{1}$ electrons and so destabilise the semi-metallic state.

This interpretation finds support by comparing the effect of $\mathrm{Nd}$ substitution with $\mathrm{Zn}$ or Mn doping. The introduction of $\mathrm{Nd}^{3+}$ into the $\mathrm{Ba}_{2} \mathrm{FeMoO}_{6}$ parent leads to a reduction in the ferrimagnetic transition temperature. This falls as a faster function of composition than it does for $\mathrm{Zn}$ or $\mathrm{Mn}$

doping and suggests that the $\mathrm{Nd}^{3+}$ cation strongly disrupts the magnetic interactions by expanding the lattice and so reducing the orbital overlap. It is this expansion that disrupts the delocalisation and raises the electronic energy. This electronic contribution serves to supplement the destabilising effect of mechanical lattice strain and so is likely to be responsible for the more limited solubility of $\mathrm{Nd}$ in the Fe-rich phase.

\section{Conclusions}

A limited solubility range exists for doping of the cation ordered perovskites in the series $B a_{2} \mathrm{Nd}_{1}$. ${ }_{x} \mathrm{Fe}_{x} \mathrm{MoO}_{6}$. The introduction of $\mathrm{Fe}^{3+}$ into the electronically localised material $\mathrm{Ba}_{2} \mathrm{NdMoO}_{6}$ leads to 
suppression of the long range antiferromagnetic ordering and instead $\mathrm{Ba}_{2} \mathrm{Nd}_{0.90} \mathrm{Fe}_{0.10} \mathrm{MoO}_{6}$ forms a spin glass. Increasing the Fe-content beyond the percolation limit for the $f c c$ lattice fails to generate a metallic state and $\mathrm{Ba}_{2} \mathrm{Nd}_{0.75} \mathrm{Fe}_{0.25} \mathrm{MoO}_{6}$ shows activated electronic conductivity indicative of fully localised electrons. A solubility gap exists for $0.30 \leq x \leq 0.85$; in this compositional range two perovskites are formed. The lattice parameters suggest that these phases are of fixed composition and the overall sample composition is maintained by varying the fraction of these two phases. Single phase compounds are formed at the Fe-richer compositions from $\mathrm{Ba}_{2} \mathrm{Nd}_{0.10} \mathrm{Fe}_{0.90} \mathrm{MoO}_{6}$ and increasing Fe-content. These phases show ferrimagnetic ordering with $\mathrm{T}_{\mathrm{c}}$ showing a strong compositional dependence, being reduced by $70 \mathrm{~K}$ in $\mathrm{Ba}_{2} \mathrm{Nd}_{0.10} \mathrm{Fe}_{0.90} \mathrm{MoO}_{6}$ compared to $\mathrm{Ba}_{2} \mathrm{FeMoO}_{6}$. $\mathrm{Ba}_{2} \mathrm{Nd}_{0.10} \mathrm{Fe}_{0.90} \mathrm{MoO}_{6}$ displays metallic conductivity and examination of the low temperature magnetic behaviour of $\mathrm{Ba}_{2} \mathrm{Nd}_{0.95} \mathrm{Fe}_{0.05} \mathrm{MoO}_{6}$ shows a long-range parallel alignment of the Fe moments indicative of ferrimagnetic ordering, but no contribution from $\mathrm{Nd}^{3+}$ or $\mathrm{Mo}^{5+}$ to the magnetic Bragg scattering. Despite the superficial structural similarities of the cation ordered phases $\mathrm{Ba}_{2} \mathrm{NdMoO}_{6}$ and $\mathrm{Ba}_{2} \mathrm{FeMoO}_{6}$ the difference in electronic behaviour introduces a compositional gap that cannot be bridged.

Supplementary Information is available free of charge and provides providing crystallographic information files, bond lengths, additional magnetisation data and neutron diffraction profiles.

Acknowledgements: We would like to thank Dr E. Suard and the ILL for technical support and providing access to neutron diffraction beamtime and the EPSRC for funding this work. Electrical conductivity measurements were possible due to the kind support of the Shared Experimental Facilities of the Materials Research Laboratory at the University of California, Santa Barbara, supported by the MRSEC Program of the NSF under Award no. DMR 1121053. 
Figure Captions:

Figure 1 The structure of the cation-ordered double perovskite $\mathrm{Ba}_{2} \mathrm{MMoO}_{6}$. Black spheres represent the barium cations and red and yellow octahedra represent the smaller $\mathrm{MoO}_{6}$ and larger $\mathrm{MO}_{6}$ octahedra respectively.

Figure 2 The phase stability ranges (upper) and phase lattice parameters (lower) for the series $\mathrm{Ba}_{2} \mathrm{Nd}_{1-x} \mathrm{Fe}_{x} \mathrm{MoO}_{6}$. In the lower trace the black circles represent the lattice parameters of the Nd-rich perovskite and the red triangles show the lattice parameter of the cubic Fe-rich phase. The shaded area represents the two-phase compositional range.

Figure 3 Observed (dots), calculated (line) and difference neutron diffraction patterns collected from a) $\mathrm{Ba}_{2} \mathrm{Nd}_{0.90} \mathrm{Fe}_{0.10} \mathrm{MoO}_{6}$ at $1.5 \mathrm{~K}$ and from b) $\mathrm{Ba}_{2} \mathrm{Nd}_{0.80} \mathrm{Fe}_{0.20} \mathrm{MoO}_{6}$ at room temperature. The quality of these fits is indicated by the parameters $\mathrm{R}_{\mathrm{wp}}=4.35, \chi^{2}=9.44$ for $\mathrm{Ba}_{2} \mathrm{Nd}_{0.90} \mathrm{Fe}_{0.10} \mathrm{MoO}_{6}$ and $\mathrm{R}_{\mathrm{wp}}=2.28, \chi^{2}=3.66$ for $\mathrm{Ba}_{2} \mathrm{Nd}_{0.80} \mathrm{Fe}_{0.20} \mathrm{MoO}_{6}$.

Figure 4 The temperature dependence of the a) Mo-O bond length and b) lattice parameters of $\mathrm{Ba}_{2} \mathrm{Nd}_{0.75} \mathrm{Fe}_{0.25} \mathrm{MoO}_{6}$ derived from neutron diffraction data. The $a$ lattice parameter is represented as $a \sqrt{2}$ to allow comparison with $c$. These are shown by circles and triangles respectively. The error bars in the bond lengths represent one estimated standard deviation in the Rietveld refinement. The errors associated with the lattice parameters are smaller than the symbol size.

Figure 5 The temperature dependence of the resistivity of $\mathrm{Ba}_{2} \mathrm{Nd}_{0.75} \mathrm{Fe}_{0.25} \mathrm{MoO}_{6}$ as a function of applied magnetic field. Data collected in zero applied field and $10000 \mathrm{G}$ are represented as circles and squares respectively.

Figure 6 The main reflections in the $\mathrm{X}$-ray diffraction patterns collected from samples of composition $\mathrm{Ba}_{2} \mathrm{Nd}_{1-x} \mathrm{Fe}_{x} \mathrm{O} 6$ in the two-phase region of the phase diagram, $0.3 \leq x \leq 0.8$. There is clear separation between the peaks from the Nd-rich phase, $2 \theta \approx 29^{\circ}$ and, the Fe-rich phase , $2 \theta \approx 30^{\circ}$.

Figure 7 Neutron diffraction data collected from $\mathrm{Ba}_{2} \mathrm{Nd}_{0.05} \mathrm{Fe}_{0.95} \mathrm{MoO}_{6}$ at $1.5 \mathrm{~K}$ and fitted using both nuclear and magnetic order to give the quality of fit parameters $R_{w p}=8.65, \chi^{2}=4.33$. The inset shows the a lowangle portion of the pattern collected from the same compound at room temperature and illustrates the loss of magnetic Bragg intensity.

Figure 8 The a) magnetic susceptibility and b) resistivity of $\mathrm{Ba}_{2} \mathrm{Nd}_{0.10} \mathrm{Fe}_{0.90} \mathrm{MoO}_{6}$ as a function of temperature. The magnetisation was collected after cooling from room temperature in either zero applied field (circles) or in the measuring field (triangles) of $1000 \mathrm{G}$. The inset in (a) shows the isothermal magnetisation as a function of applied field at $2 \mathrm{~K}$. The resistivity in (b) was measured in either zero applied magnetic field, shown by red circles, or in an applied field of $10000 \mathrm{G}$, shown by black squares. Data were collected on cooling and then on heating; this showed no history dependence in the applied field but the zero applied field data diverge above ca. $250 \mathrm{~K}$ as indicated. 
Figure 9 a) The magnetization of $\mathrm{Ba}_{2} \mathrm{Nd}_{0.05} \mathrm{Fe}_{0.95} \mathrm{MoO}_{6}$ collected in a measuring field of $100 \mathrm{G}$ after zero field cooling (circles) and cooling in the measuring field (triangles). The magnetisation rises rapidly $\leq 280 \mathrm{~K} . \mathrm{b}$ ) Magnetisation measured at $1.5 \mathrm{~K}$ shows a clear saturation occurring at around $3 \mu_{\mathrm{B}}$ per formula unit. 


\section{References}

1. P. M. Woodward, Acta Cryst. 1997, B53, 32.

2. C. J. Howard; B. J. Kennedy; P. M. Woodward, Acta Cryst. 2003, B59, 463.

3. N. S. P. Bhuvanesh; J. Gopalakrishnan, J. Mater. Chem. 1997, 7 (12), 2297.

4. E. J. Cussen; D. R. Lynham; J. Rogers, Chem. Mater. 2006, 18, 2855.

5. T. Aharen; J. E. Greedan; C. A. Bridges; A. A. Aczel; J. Rodriguez; G. MacDougall; G. M. Luke; T. Imai; V. K. Michaelis; S. Kroeker; H. D. Zhou; C. R. Wiebe; L. M. D. Cranswick, Phys. Rev. B 2010, 81 (22), 224409.

6. A. S. Erickson; S. Misra; G. J. Miller; R. R. Gupta; Z. Schlesinger; W. A. Harrison; J. M. Kim; I. R. Fisher, Phys. Rev. Lett. 2007, 99 (1), 016404.

7. M. A. de Vries; A. C. McLaughlin; J. W. G. Bos, Phys. Rev. Lett. 2010, 104 (17), 177202.

8. F. C. Coomer; E. J. Cussen, J. Phys.: Condens. Matter 2013, 25 (8), 082202.

9. A. A. Aczel; D. E. Bugaris; J. Yeon; C. de la Cruz; H. C. zur Loye; S. E. Nagler, Phys. Rev. B 2013, 88 (1), 014413.

10. H. Ishizuka; L. Balents, Phys. Rev. B 2014, 90 (18), 184422.

11. B. H. Yan; A. K. Paul; S. Kanungo; M. Reehuis; A. Hoser; D. M. Toebbens; W. Schnelle; R. C. Williams; T. Lancaster; F. Xiao; J. S. Moller; S. J. Blundell; W. Hayes; C. Felser; M. Jansen, Phys. Rev. Lett. 2014, 112 (14), 147202.

12. A. C. Mclaughlin, Solid State Commun. 2006, 137, 354.

13. A. C. Mclaughlin, Phys. Rev. B 2008, 78, 132404.

14. E. J. Cussen; W. J. Cameron, J. Mater. Chem. 2010, 20 (7), 1340.

15. O. M. Collins; E. J. Cussen, J. Solid State Chem. 2013, 200, 215.

16. T. K. Wallace; R. H. Colman; A. C. McLaughlin, PCCP 2013, 15, 8672.

17. F. C. Coomer; E. J. Cussen, Inorg. Chem. 2014, 53, 746.

18. S. Calder; X. Ke; F. Bert; A. Amato; C. Baines; C. Carboni; R. J. Cava; A. Daoud-Aladine; P. Deen; T. Fennell; A. D. Hillier; H. Karunadasa; J. W. Taylor; P. Mendels; P. Schiffer; S. T. Bramwell, Phys. Rev. B 2010, $81(6)$.

19. T. Aharen; J. E. Greedan; C. A. Bridges; A. A. Aczel; J. Rodriguez; G. MacDougall; G. M. Luke; V. K. Michaelis; S. Kroeker; C. R. Wiebe; H. D. Zhou; L. M. D. Cranswick, Phys. Rev. B 2010, 81 (6).

20. T. Aharen; J. E. Greedan; F. Ning; T. Imai; V. Michaelis; S. Kroeker; H. D. Zhou; C. R. Wiebe; L. M. D. Cranswick, Phys. Rev. B 2009, 80 (13).

21. A. Maignan; B. Raveau; C. Martin; M. Hervieu, J. Solid State Chem. 1999, 144, 224.

22. F. Sriti; A. Maignan; C. Martin; B. Raveau, Chem. Mater. 2001, 13 (5), 1746.

23. C. Ritter; M. R. Ibarra; L. Morellon; J. Blasco; J. Garcia; J. M. De Teresa, J. Phys. Condens. Matter 2000, 12, 8295.

24. K. I. Kobayashi; T. Kimura; Y. Tomioka; H. Sawada; K. Terakura; Y. Tokura, Phys. Rev. B 1999, 59 (17), 11159.

25. K.-I. Kobayashi; T. Kimura; H. Sawada; K. Terakura; Y. Tokura, Nature 1998, 395.

26. A. K. Azad; S.-G. Eriksson; S. A. Ivvanov; R. Mathieu; S. P. Svedlindh; J. Eriksen; H. Rundlof, J. Alloys Compd. 2004, 364, 77.

27. E. J. Cussen, J. Solid State Chem. 2007, 180 (2).

28. R. A. Cowley, Phil. Trans. R. Soc. Lond. 1980, B 290, 583.

29. B. C. Tofield; B. E. F. Fender, J. Phys. Chem. Solids 1970, 31, 2741. 


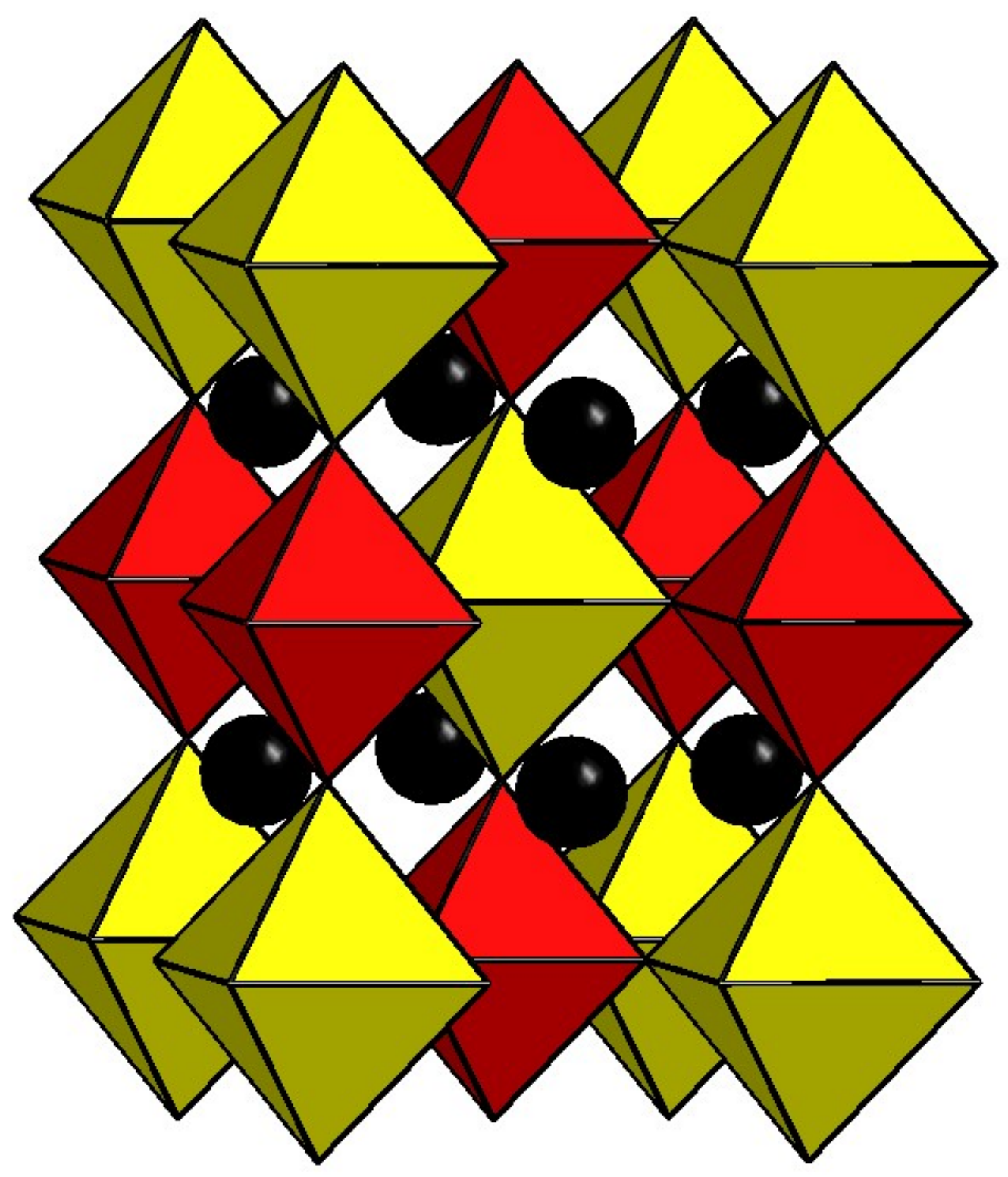

Figure 1 The structure of the cation-ordered double perovskite $\mathrm{Ba}_{2} \mathrm{MMoO}_{6}$. Black spheres represent the barium cations and red and yellow octahedra represent the smaller $\mathrm{MoO}_{6}$ and larger $\mathrm{MO}_{6}$ octahedra respectively. 


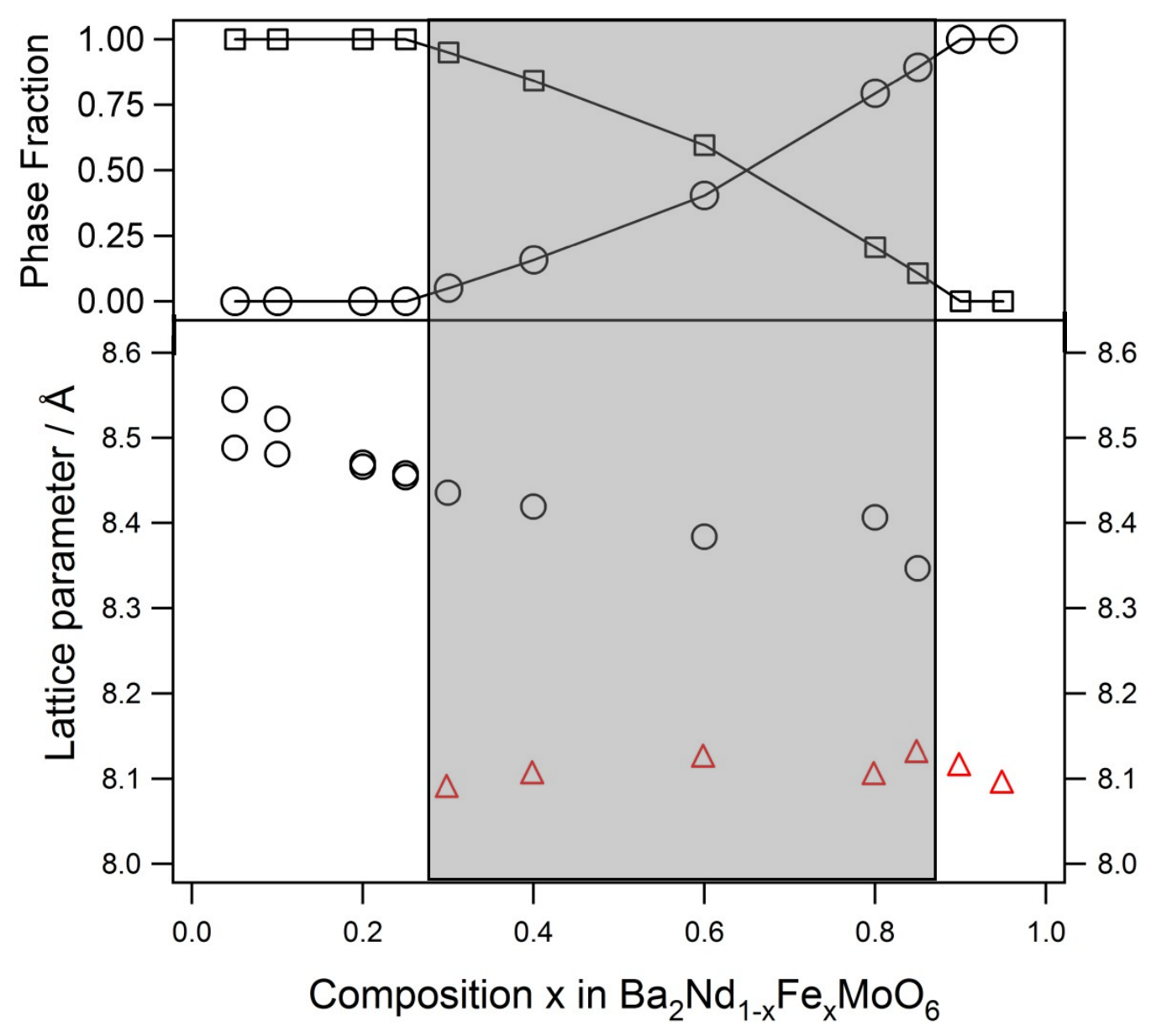

Figure 2 The phase stability ranges (upper) and phase lattice parameters (lower) for the series $\mathrm{Ba}_{2} \mathrm{Nd}_{1-x} \mathrm{Fe}_{x} \mathrm{MoO}_{6}$. In the lower trace the black circles represent the lattice parameters of the $\mathrm{Nd}$-rich perovskite and the red triangles show the lattice parameter of the cubic $\mathrm{Fe}$-rich phase. The shaded area represents the two-phase compositional range. 


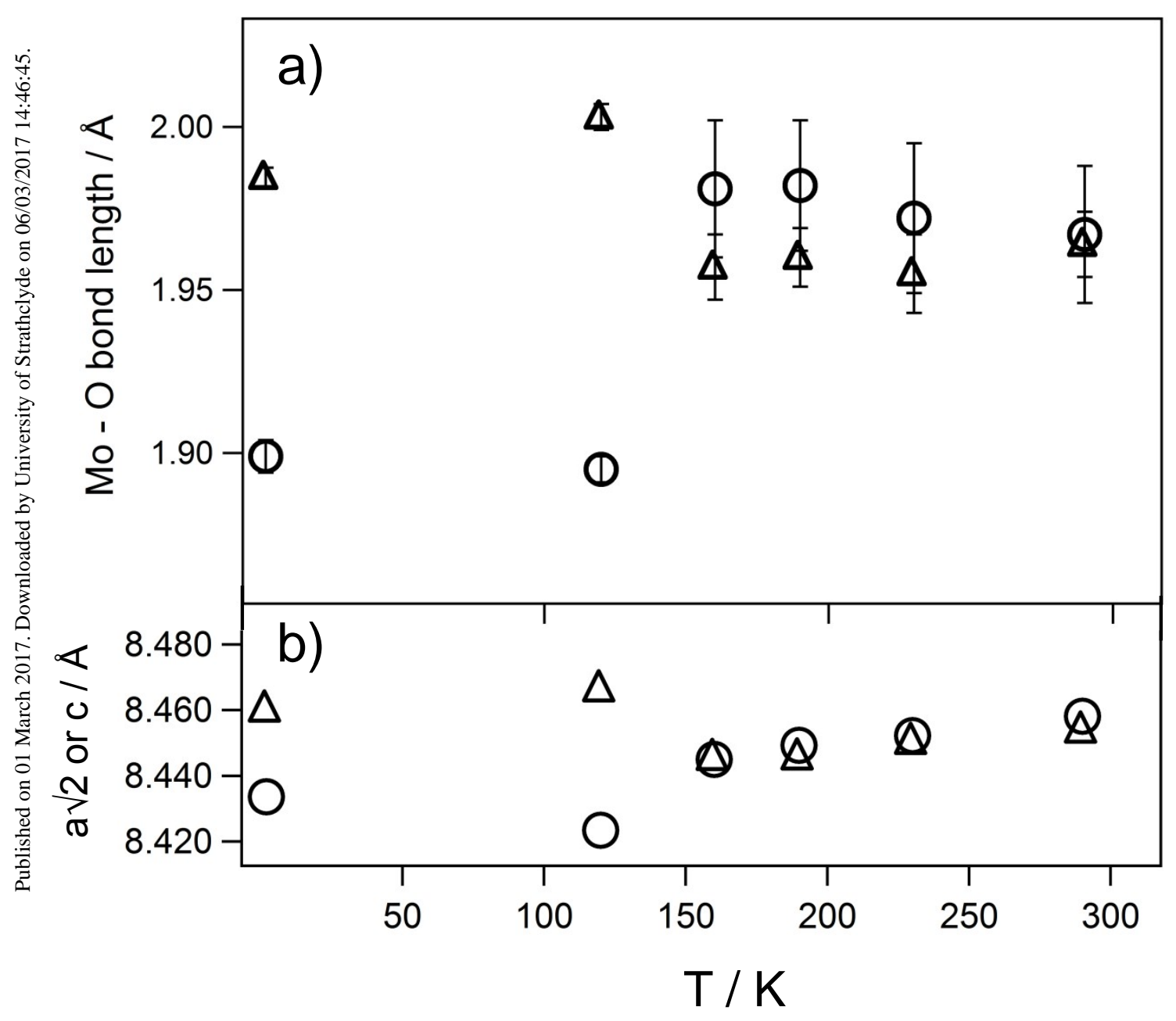

Figure 4 The temperature dependence of the a) Mo-O bond length and b) lattice parameters of $\mathrm{Ba}_{2} \mathrm{Nd}_{0.75} \mathrm{Fe}_{0.25} \mathrm{MoO}_{6}$ derived from neutron diffraction data. The a lattice parameter is represented as $\mathrm{a} \sqrt{2}$ to allow comparison with $\mathrm{c}$. These are shown by circles and triangles respectively. The error bars in the bond lengths represent one estimated standard deviation in the Rietveld refinement. The errors associated with the lattice parameters are smaller than the symbol size. 


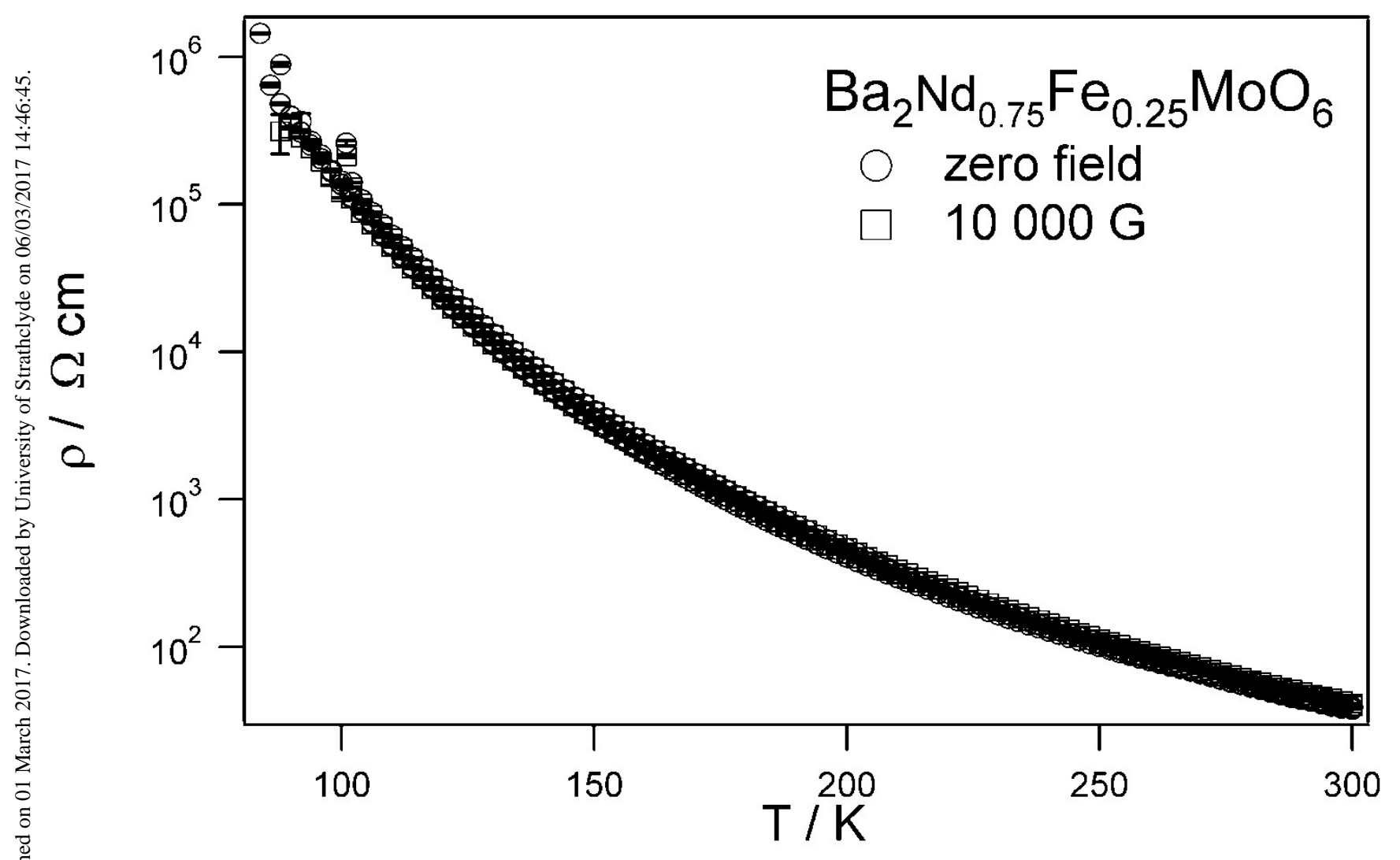

Figure 5 The temperature dependence of the resistivity of $\mathrm{Ba}_{2} \mathrm{Nd}_{0.75} \mathrm{Fe}_{0.25} \mathrm{MoO}_{6}$ as a function of applied magnetic field. Data collected in zero applied field and $10000 \mathrm{G}$ are represented as circles and squares respectively. 


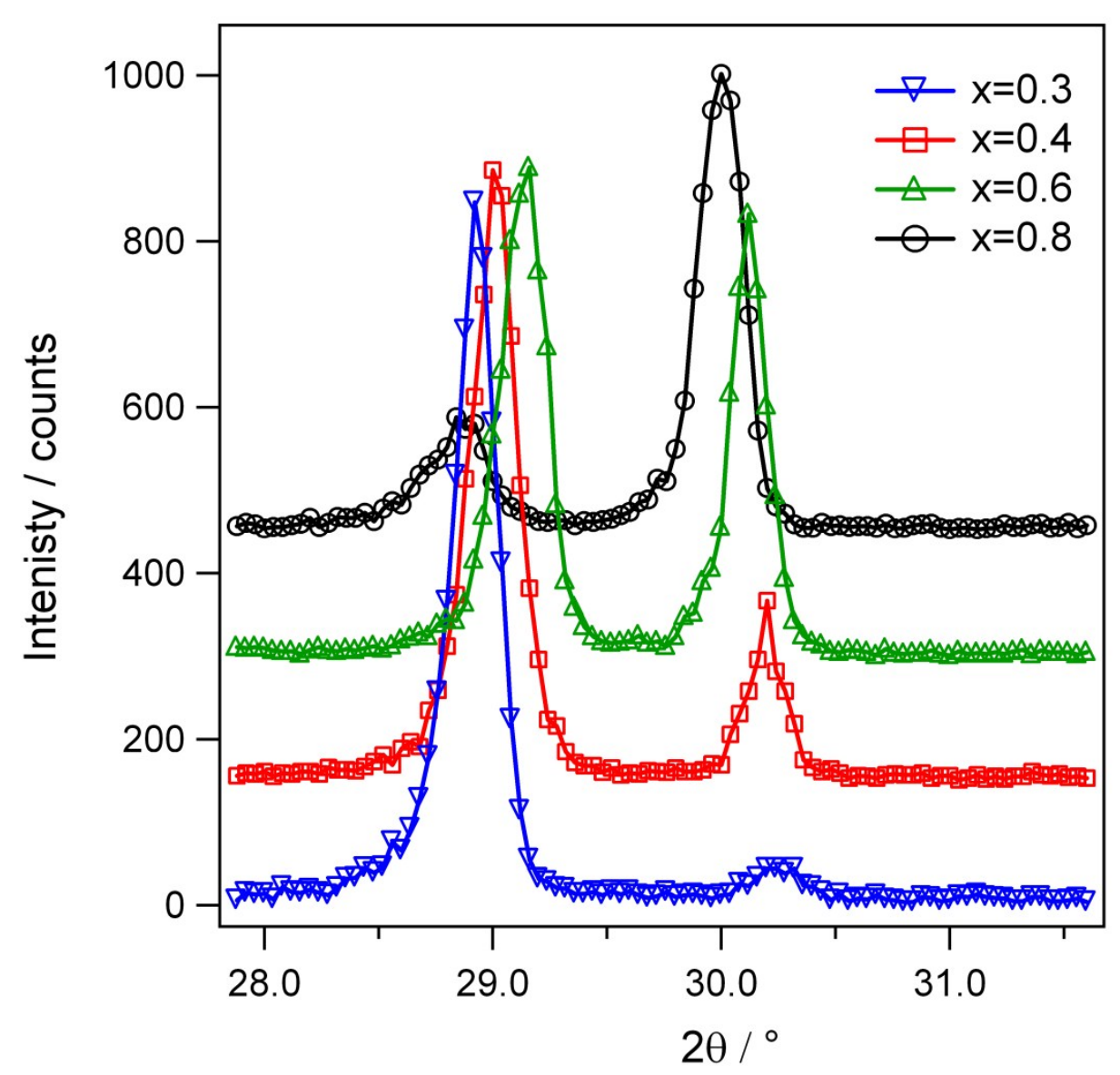

Figure 6 The main reflections in the $\mathrm{X}$-ray diffraction patterns collected from samples of composition $\mathrm{Ba}_{2} \mathrm{Nd}_{1-\mathrm{x}} \mathrm{Fe}_{\mathrm{x}} \mathrm{O}_{6}$ in the two-phase region of the phase diagram. There is clear separation between the peaks from the Nd-rich phase, $2 \theta \approx$ $29^{\circ}$ and, the Fe-rich phase , $2 \theta \approx 30$. 


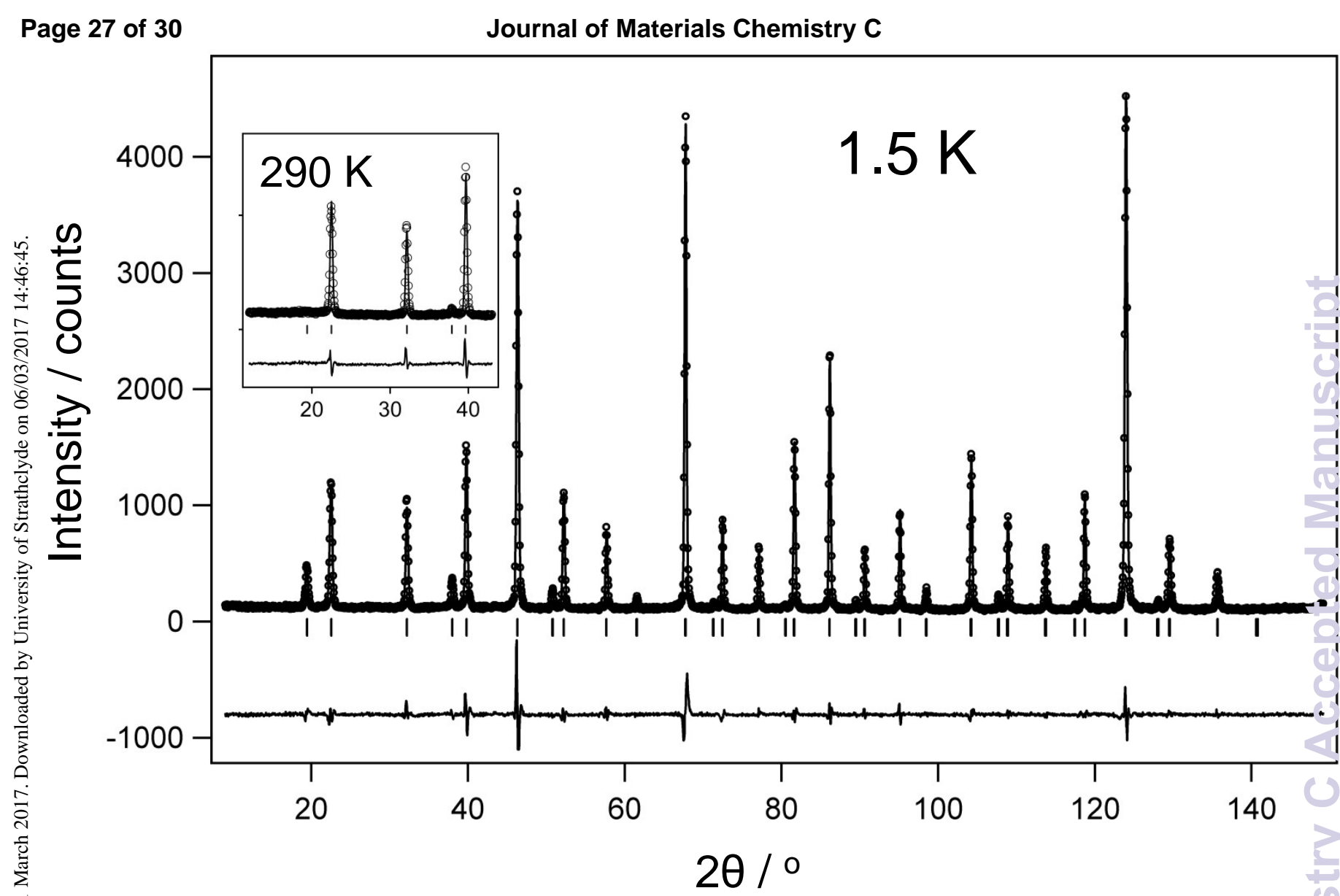

Figure 7 Neutron diffraction data collected from $\mathrm{Ba}_{2} \mathrm{Nd}_{0.05} \mathrm{Fe}_{0.95} \mathrm{MoO}_{6}$ at $1.5 \mathrm{~K}$ and fitted using both nuclear and magnetic order to give the quality of fit parameters $R_{w p}$ $=8.65, X^{2}=4.33$. The inset shows the a low-angle portion of the pattern collected from the same compound at room temperature and illustrates the loss of magnetic Bragg intensity. 

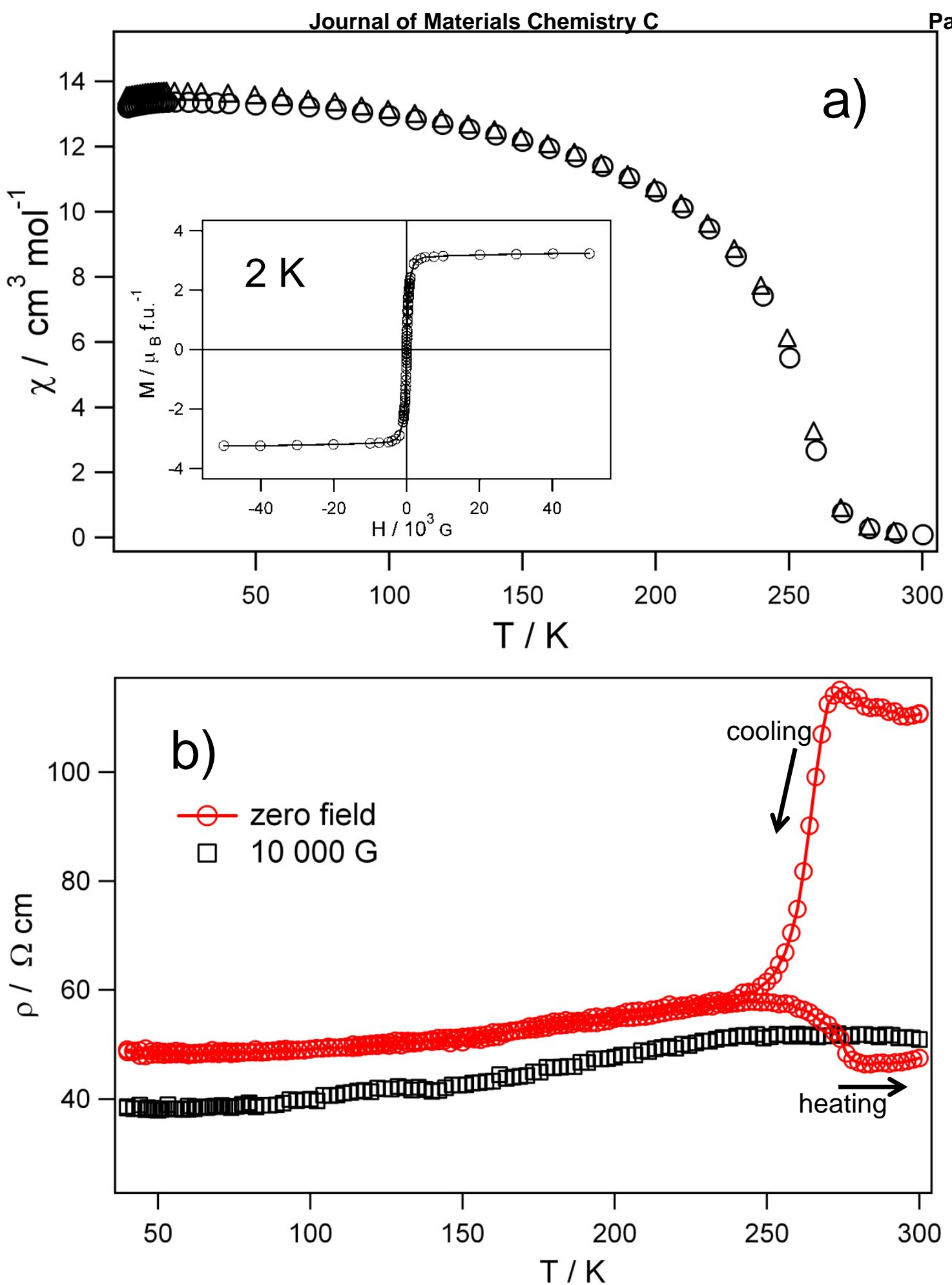

Figure 8 The a) magnetic susceptibility and b) resistivity of $\mathrm{Ba}_{2} \mathrm{Nd}_{0.10} \mathrm{Fe}_{0.90} \mathrm{MoO}_{6}$ as a function of temperature. The magnetisation was collected after cooling from room temperature in either zero applied field (circles) or in the measuring field (triangles) of $1000 \mathrm{G}$. The inset in (a) shows the isothermal magnetisation as a function of applied field at $2 \mathrm{~K}$. The resistivity in (b) was measured in either zero applied magnetic field, shown by red circles, or in an applied field of $10000 \mathrm{G}$, shown by black squares. Data were collected on cooling and then on heating; this showed no history dependence in the applied field but the zero applied field data diverge above ca. $250 \mathrm{~K}$ as indicated. 

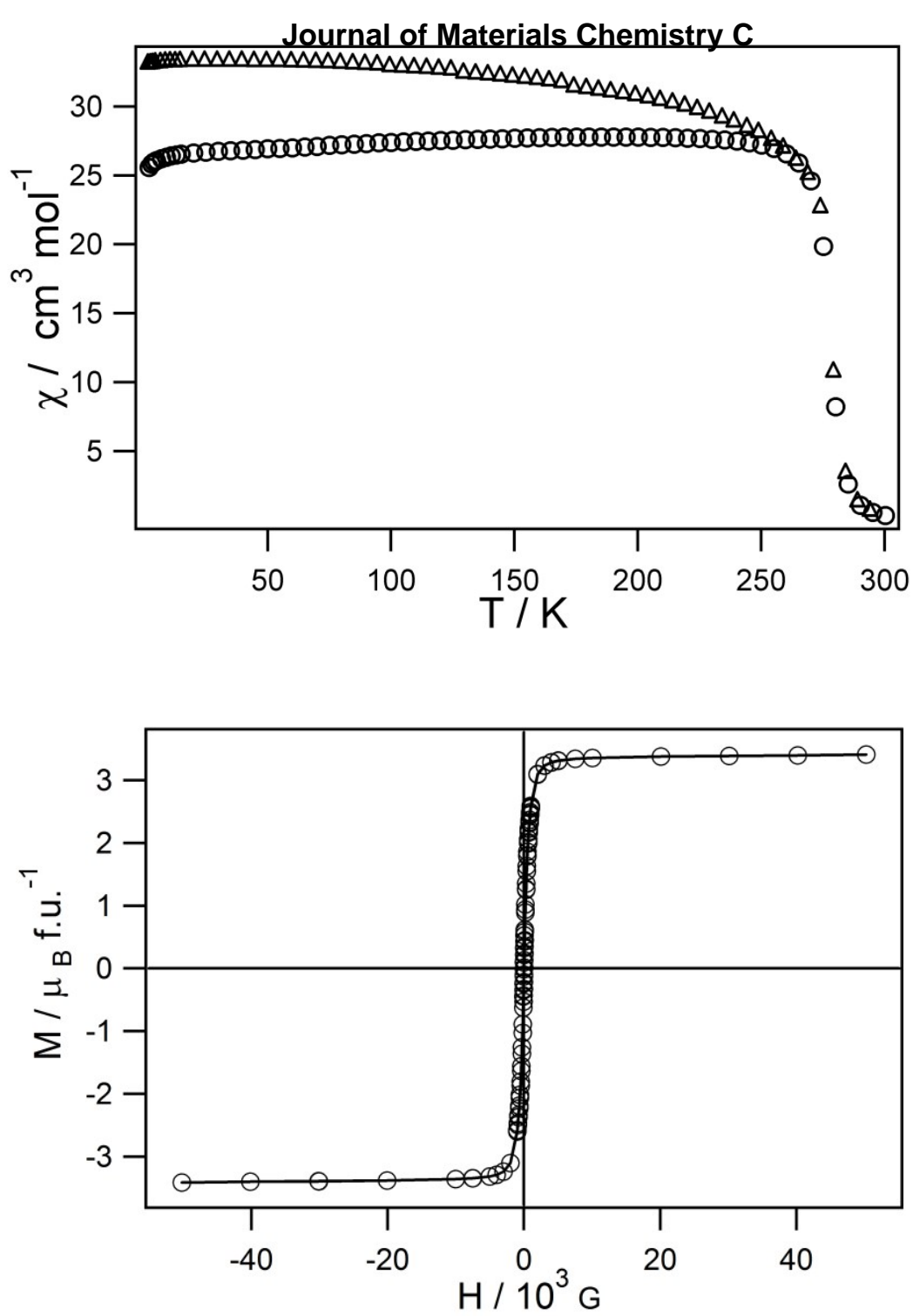

Figure 9 a) The magnetization of $\mathrm{Ba}_{2} \mathrm{Nd}_{0.05} \mathrm{Fe}_{0.95} \mathrm{MoO}_{6}$ in collected in a measuring field of $100 \mathrm{G}$ after zero field cooling (circles) and cooling in the measuring field (triangles). The magnetisation rises rapidly $\leq 280 \mathrm{~K}$. b) Magnetisation measured at $1.5 \mathrm{~K}$ shows a clear saturation occurring at around $3 \mu_{\mathrm{B}}$ per formula unit. 

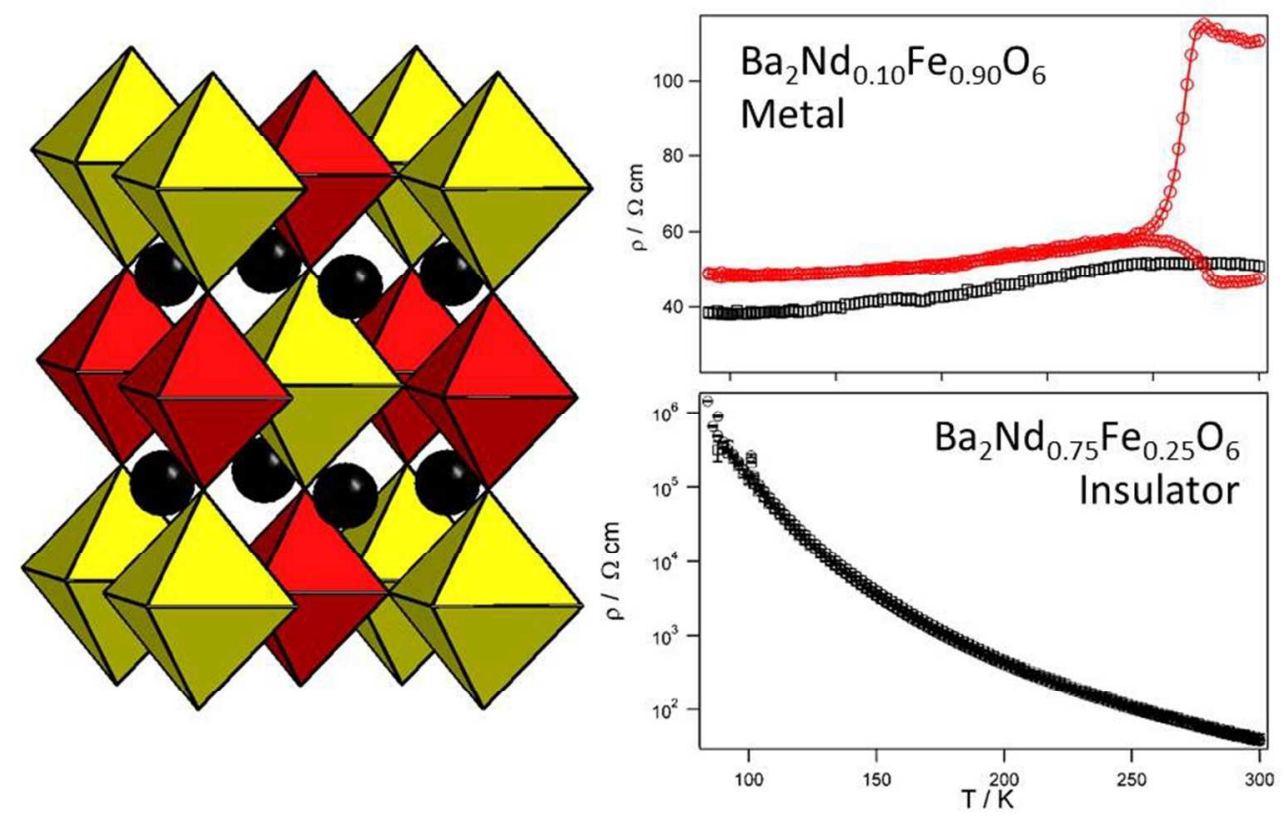

246×157mm (96 x 96 DPI) 


\section{SUPPLEMENTARY INFORMATION}

\section{Insulating to Metallic behaviour in the Cation Ordered Perovskites $\mathrm{Ba}_{2} \mathrm{Nd}_{1-x} \mathrm{Fe}_{x} \mathrm{MoO}_{6}$}

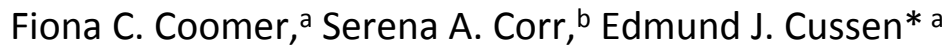

Pages 2 - 8 Crystallographic Information from Rietveld Refinment against neutron diffraction data.

Pages $9-13$ Supplementary Figures

Figure $\mathrm{S} 1$ The bond lengths for Mo-O (black circles) and $\mathrm{Nd} / \mathrm{Fe}-\mathrm{O}$ (triangles) derived from refinement against neutron diffraction data collected at room temperature.

Figure $\mathrm{S} 2$ Neutron diffraction profiles collected at room temperature and $1.5 \mathrm{~K}$ from Ba${ }_{2} \mathrm{Nd}_{0.75} \mathrm{Fe}_{0.25} \mathrm{MoO}_{6}$. Experimental and calculated profiles are shown as points and lines respectively. The vertical markers indicate the positions of allowed Bragg reflections from the tetragonal perovskite (upper marks) and the iron impurity (lower marks). The quality of fit is indicated by the parameters $R_{w p}=3.90, \chi^{2}=6.94$ for $290 \mathrm{~K}$ and $R_{w p}=5.14, \chi^{2}=12.07$ for the data collected at $1.5 \mathrm{~K}$.

Figure $\mathrm{S} 3$ Magnetic susceptibility data collected from (top) $\mathrm{Ba}_{2} \mathrm{Nd}_{0.95} \mathrm{Fe}_{0.05} \mathrm{MoO}_{6}$ in $1000 \mathrm{G}$ field, (middle) $\mathrm{Ba}_{2} \mathrm{Nd}_{0.90} \mathrm{Fe}_{0.10} \mathrm{MoO}_{6}$ in $1000 \mathrm{G}$ field and (bottom) $\mathrm{Ba}_{2} \mathrm{Nd}_{0.80} \mathrm{Fe}_{0.20} \mathrm{MoO}_{6}$ in $100 \mathrm{G}$ field. Data are were collected after cooling in either zero applied magnetic field (circles) or after cooling in the measuring field cooled (triangles). The inset shows the Curie Weiss fit to the inverse susceptibility.

Figure $\mathrm{S} 4$ The temperature dependence of the resistivity of $\mathrm{Ba}_{2} \mathrm{Nd}_{0.05} \mathrm{Fe}_{0.95} \mathrm{MoO}_{6}$ as a function of applied magnetic field. Data collected in zero applied field and $10000 \mathrm{G}$ are represented as black and red circles respectively. 
Figure S5 The long-range ordered magnetic moment in $\mathrm{Ba}_{2} \mathrm{Nd}_{0.95} \mathrm{Fe}_{0.05} \mathrm{MoO}_{6}$ derived from fitting neutron diffraction data collected at various temperatures between $1.5 \mathrm{~K}$ and room temperature.

The error bars indicate one standard deviation in the Rietveld refinement. 
$\mathrm{Ba}_{2} \mathrm{Nd}_{0.9} \mathrm{Fe}_{0.1} \mathrm{MoO}_{6}$ Room Temperature Structure

\# 8. Phase information from GSAS

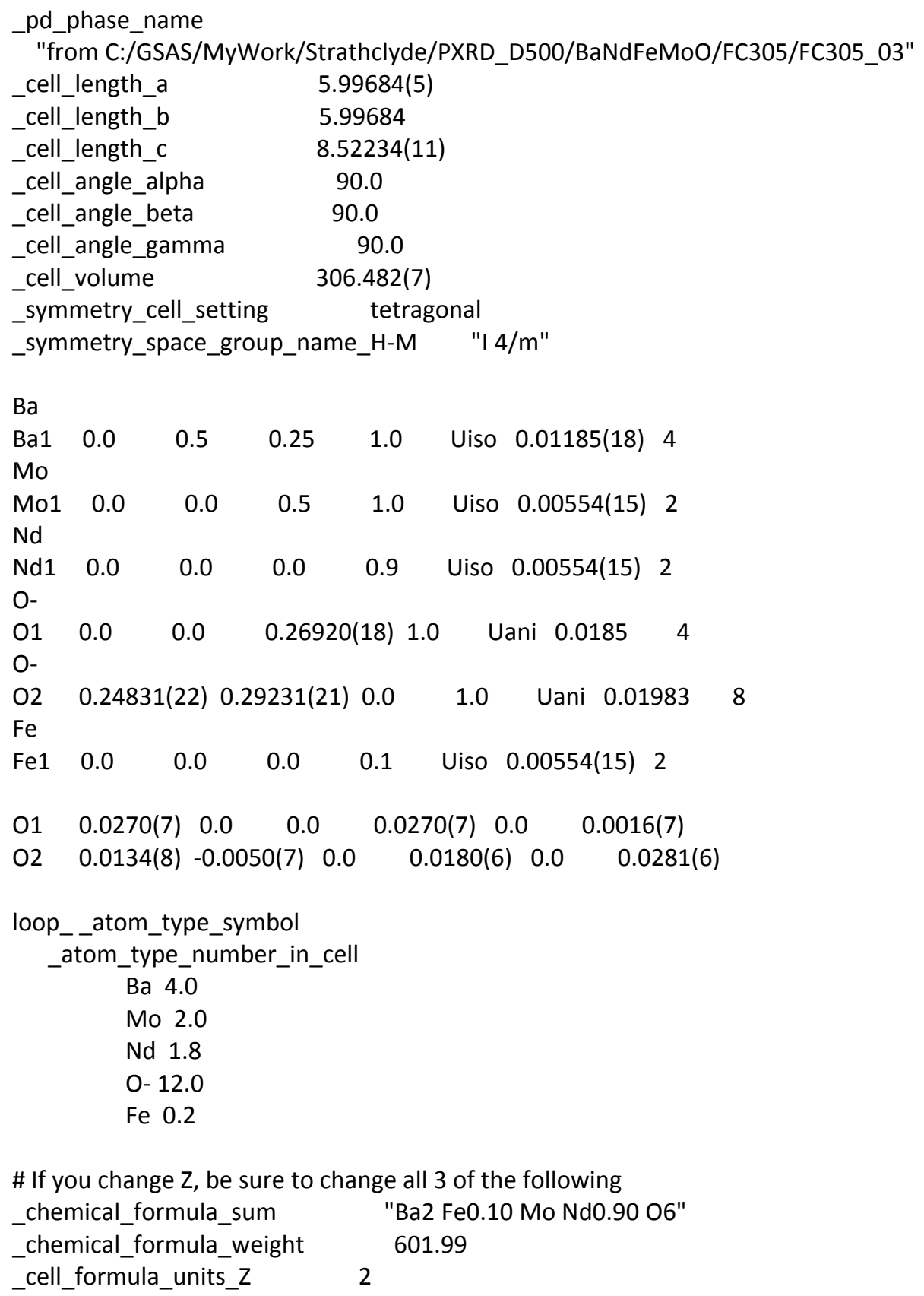


\# 8. Phase information from GSAS

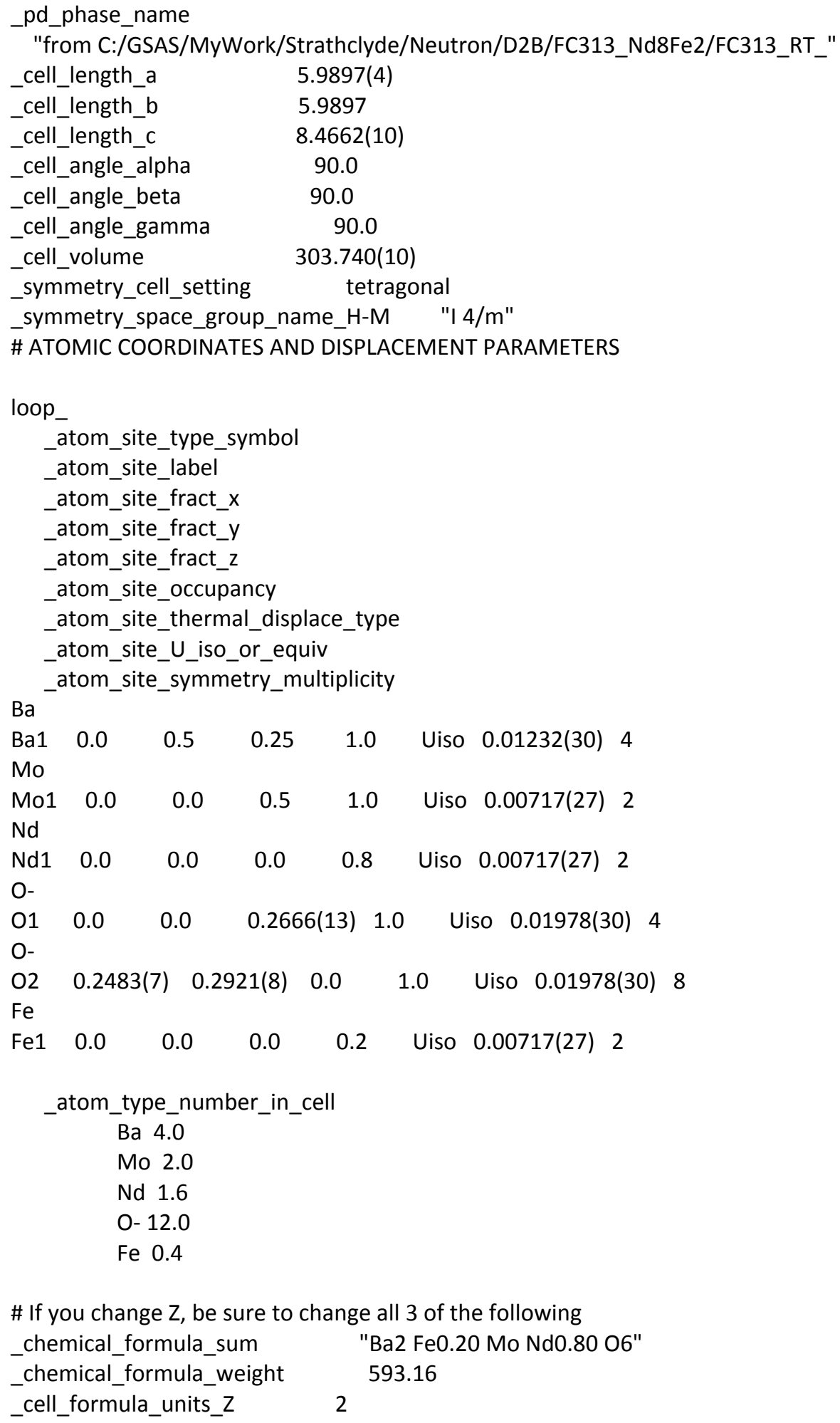

\# If you change $Z$, be sure to change all 3 of the following _chemical_formula_sum "Ba2 Fe0.20 Mo Nd0.80 06" _chemical_formula_weight 593.16

_cell_formula_units_z 2 
$\mathrm{Ba}_{2} \mathrm{Nd}_{0.75} \mathrm{Fe}_{0.25} \mathrm{MoO}_{6}$ Structure at Room Temperature

\# 8. Phase information from GSAS

_pd_phase_name

_cell_length_a

_cell_length_b

_cell_length_c

_cell_angle_alpha

_cell_angle_beta

_cell_angle_gamma

_cell_volume

_symmetry_cell_setting

_symmetry_space_group_name_H-M "I 4/m"

\section{\# ATOMIC COORDINATES AND DISPLACEMENT PARAMETERS}

loop_

atom_site_type_symbol

_atom_site_label

_atom_site_fract_x

_atom_site_fract_y

_atom_site_fract_z

_atom_site_occupancy

_atom_site_thermal_displace_type

_atom_site_U_iso_or_equiv

_atom_site_symmetry_multiplicity

$\mathrm{Ba}$

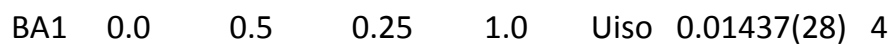

$\mathrm{Nd}$

$\begin{array}{lllllll}\text { ND1 } & 0.0 & 0.0 & 0.0 & 0.75 & \text { Uiso } & 0.00728(20)\end{array}$

$\mathrm{Fe}$

$\begin{array}{lllllll}\text { Fe1 } & 0.0 & 0.0 & 0.0 & 0.25 & \text { Uiso } & 0.00728(20)\end{array}$

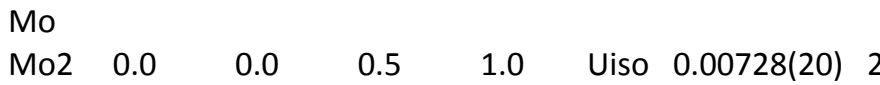

$\mathrm{O}$

$\begin{array}{lllllll}\mathrm{O}(1) & 0.0 & 0.0 & 0.2673(25) & 1.0 & \text { Uiso } & 0.0246(23)\end{array}$

0

$\begin{array}{lllllll}\mathrm{O}(2) & 0.2501(13) & 0.2870(12) & 0.0 & 1.0 & \text { Uiso } & 0.0184(9)\end{array}$

loop__atom_type_symbol

_atom_type_number_in_cell

Ba 4.0

$\mathrm{Nd} 1.5$

Fe 0.5

Mo 2.0

O 12.0

\# If you change $Z$, be sure to change all 3 of the following _chemical_formula_sum _chemical_formula_weight "Ba2 Fe0.25 Mo Nd0.75 O6" _cell_formula_units_z

\begin{abstract}
588.74
\end{abstract}


$\mathrm{Ba}_{2} \mathrm{Nd}_{0.75} \mathrm{Fe}_{0.25} \mathrm{MoO}_{6}$ Structure at $2 \mathrm{~K}$

\# 8. Phase information from GSAS

_pd_phase_name

"from C:/GSAS/MyWork/Strathclyde/Neutron/D2B/FC308_Nd75Fe25/FC308_1"

_cell_length_a

_cell_length_b

$5.96349(21)$

_cell_length_c

5.96349

$8.4607(5)$

_cell_angle_alpha

90.0

_cell_angle_beta

_cell_angle_gamma

90.0

_cell_volume

90.0

_symmetry_cell_setting

$300.890(30)$

_symmetry_space_group_name_H-M "I 4/m"

\section{\# ATOMIC COORDINATES AND DISPLACEMENT PARAMETERS}

loop_

_atom_site_type_symbol

_atom_site_label

_atom_site_fract_x

_atom_site_fract_y

_atom_site_fract_z

_atom_site_occupancy

_atom_site_thermal_displace_type

_atom_site_U_iso_or_equiv

$\mathrm{Ba}$

_atom_site_symmetry_multiplicity

$\begin{array}{lllllll}\text { Ba1 } & 0.0 & 0.5 & 0.25 & 1.0 & \text { Uiso } & 0.0110(4)\end{array}$

Mo

$\begin{array}{lllllll}\text { Mo1 } & 0.0 & 0.0 & 0.5 & 1.0 & \text { Uiso } & 0.00731(33)\end{array}$

$\mathrm{Nd}$

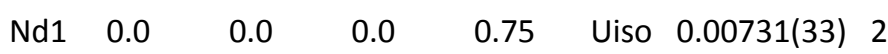

O-

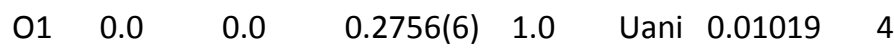

$0-$

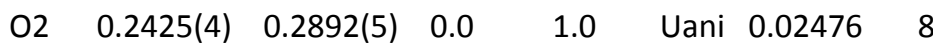

$\mathrm{Fe}$

$\begin{array}{lllllll}\text { Fe1 } & 0.0 & 0.0 & 0.0 & 0.25 & \text { Uiso } & 0.00731(33)\end{array}$

$\begin{array}{lllllll}01 & 0.0101(16) & 0.0 & 0.0 & 0.0101(16) & 0.0 & 0.0103(16)\end{array}$

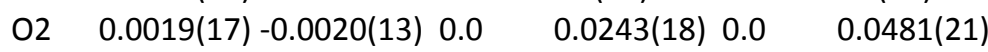

loop__atom_type_symbol

_atom_type_number_in_cell

Ba 4.0

Mo 2.0

Nd 1.5

O- 12.0

Fe 0.5

\# If you change $Z$, be sure to change all 3 of the following

_chemical_formula_sum

"Ba2 Fe0.25 Mo Nd0.75 O6"

_chemical_formula_weight

588.74

_cell_formula_units_Z 
$\mathrm{Ba}_{2} \mathrm{Nd}_{0.10} \mathrm{Fe}_{0.90} \mathrm{MoO}_{6}$ Room Temperature Structure

\# 8. Phase information from GSAS

_pd_phase_name

"from C:/gsas/MyWork/Strathclyde/PXRD_D500/BaNdFeMoO/FC314/FC314_02"

_cell_length_a

$8.11566(4)$

_cell_length_b

8.11566

_cell_length_c

8.11566

_cell_angle_alpha

90.0

90.0

_cell_angle_beta

90.0

_cell_volume

$534.530(9)$

_symmetry_cell_setting_cubic

_symmetry_space_group_name_H-M "F m -3 m"

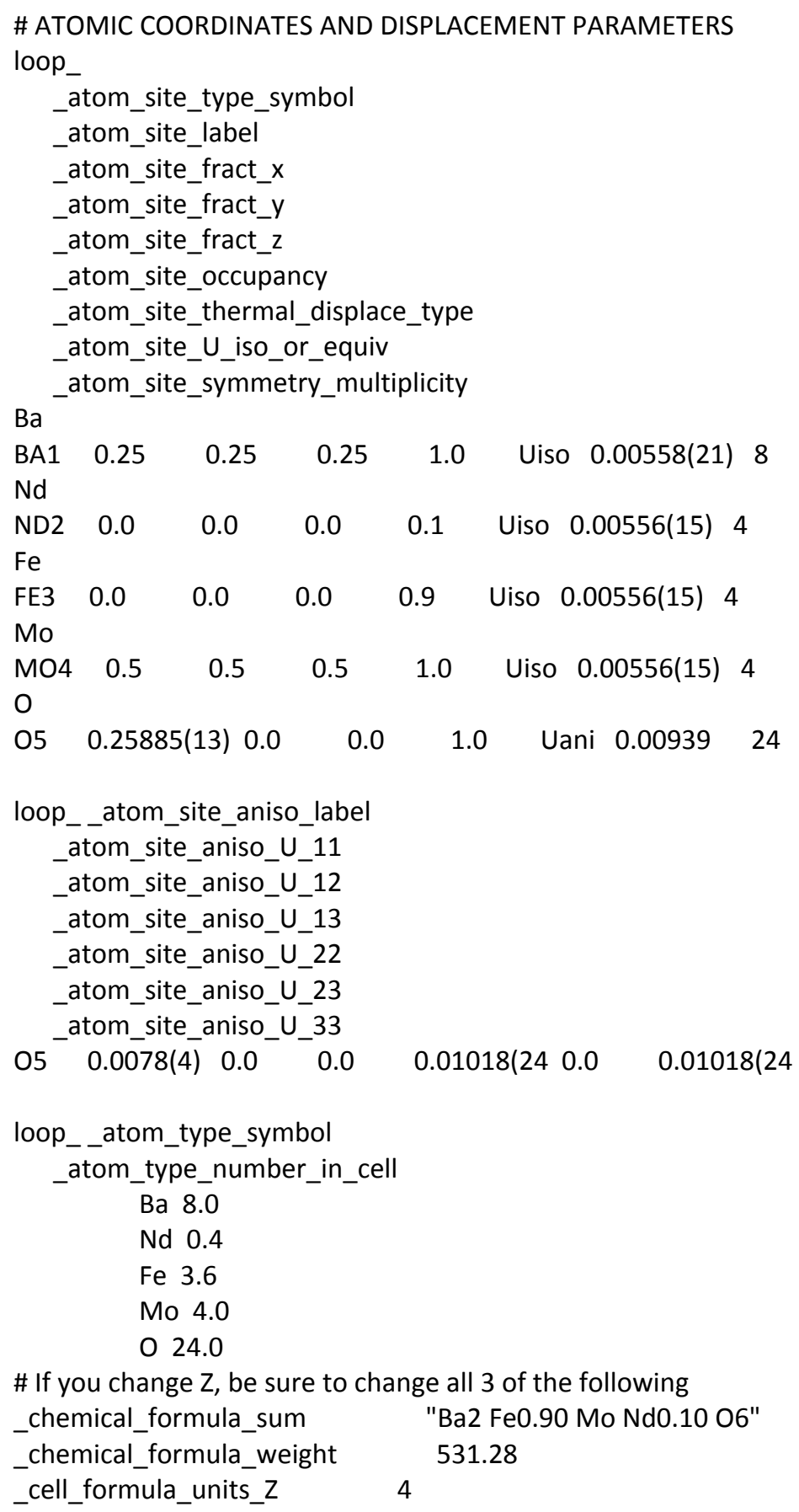


$\mathrm{Ba}_{2} \mathrm{Nd}_{0.05} \mathrm{Fe}_{0.95} \mathrm{MoO}_{6}$ Room Temperature Structure

\# 8. Phase information from GSAS

_pd_phase_name

"from C:/gsas/MyWork/Strathclyde/PXRD_D500/BaNdFeMoO/FC316/FC316_02"

_cell_length_a

8.09519(4)

_cell_length_b

8.09519

_cell_length_c

8.09519

_cell_angle_alpha

90.0

_cell_angle_beta

_cell_angle_gamma

90.0

_cell_volume

90.0

_symmetry_cell_setting_cubic

_symmetry_space_group_name_H-M "F m -3 m"

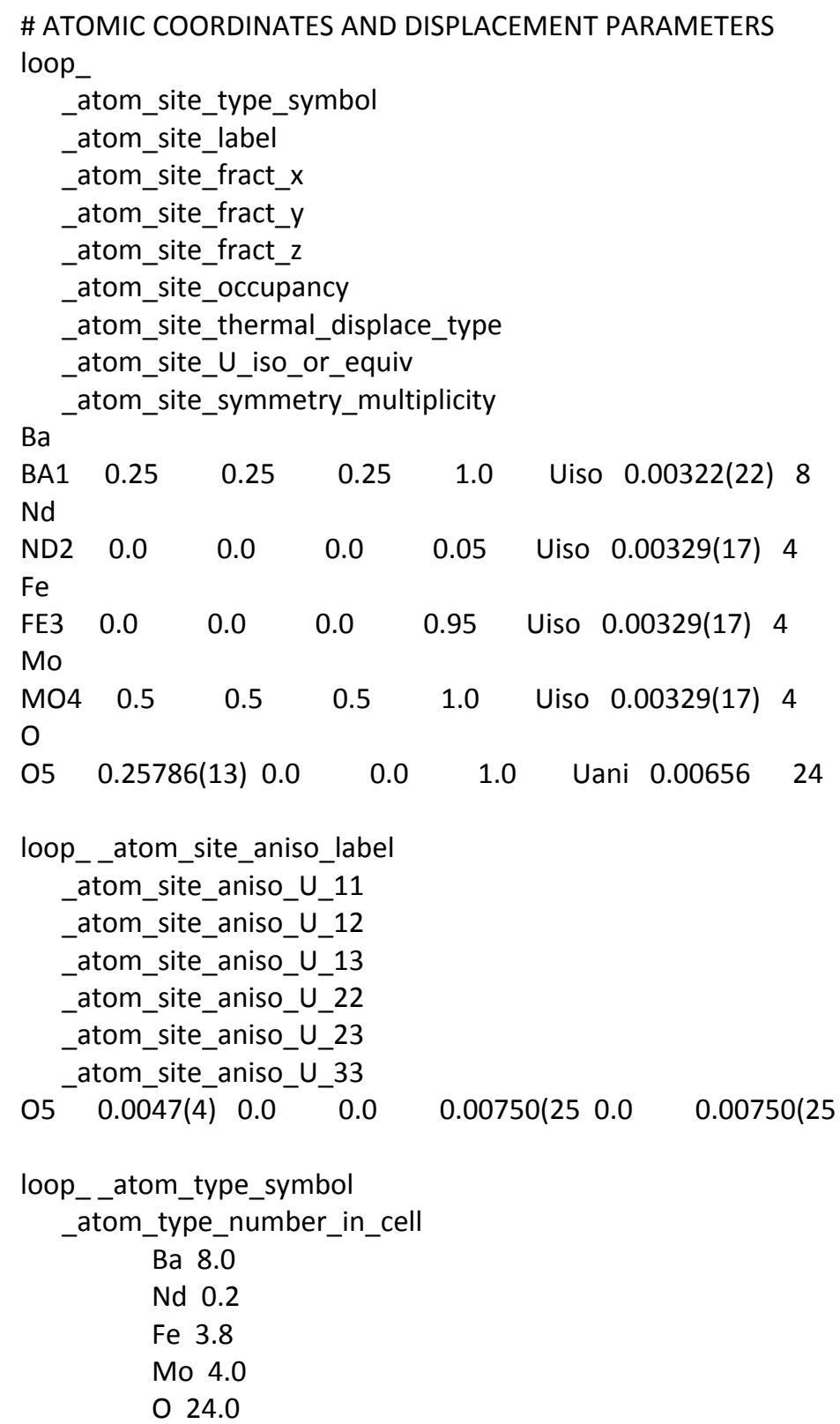

\# If you change $Z$, be sure to change all 3 of the following _chemical_formula_sum "Ba2 Fe0.95 Mo Nd0.05 06" _chemical_formula_weight 526.86 _cell_formula_units_Z 4 


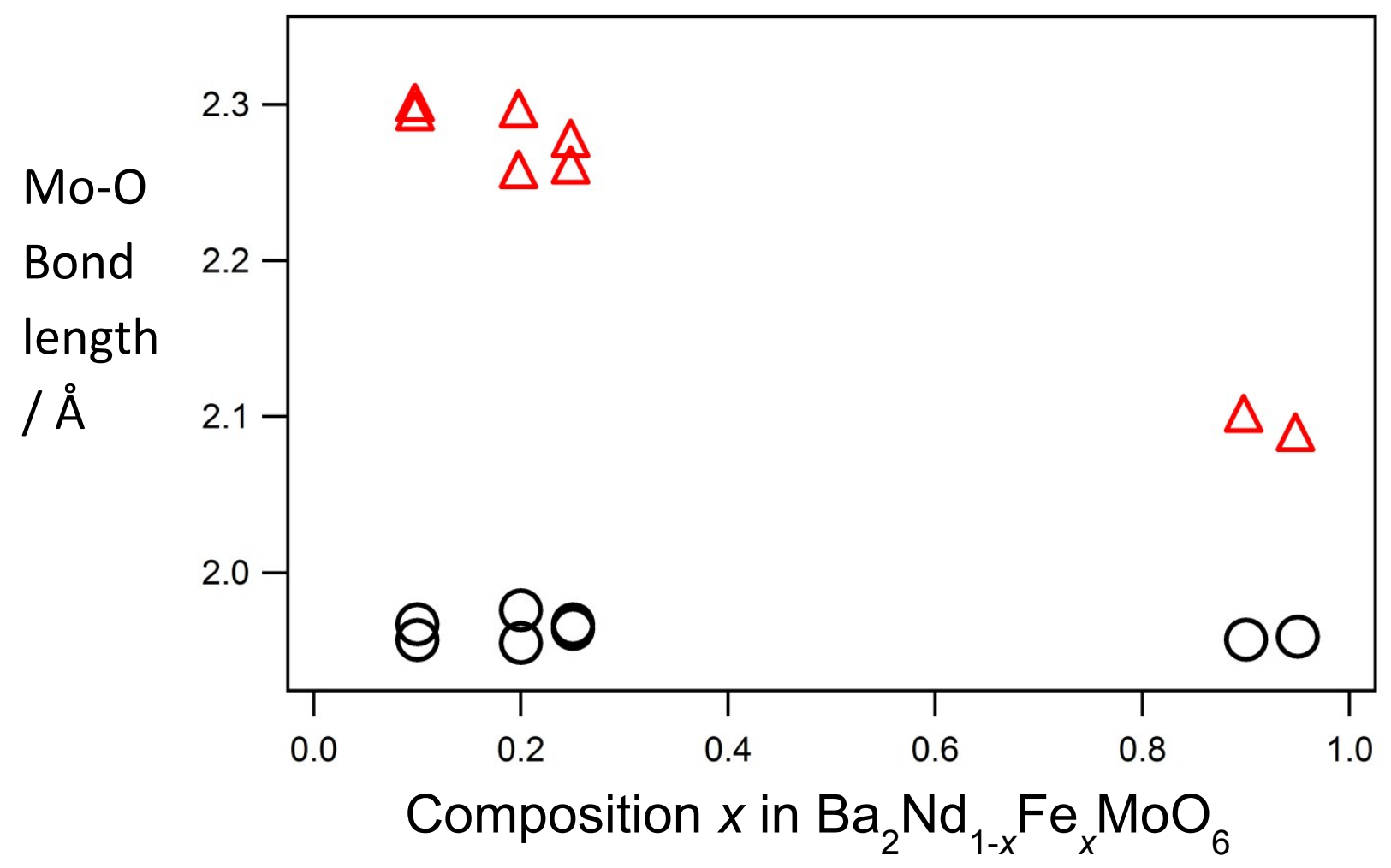

Figure S1

The bond lengths for Mo-O (black circles) and $\mathrm{Nd} / \mathrm{Fe}-\mathrm{O}$ (triangles) derived from refinement against neutron diffraction data collected at room temperature. 

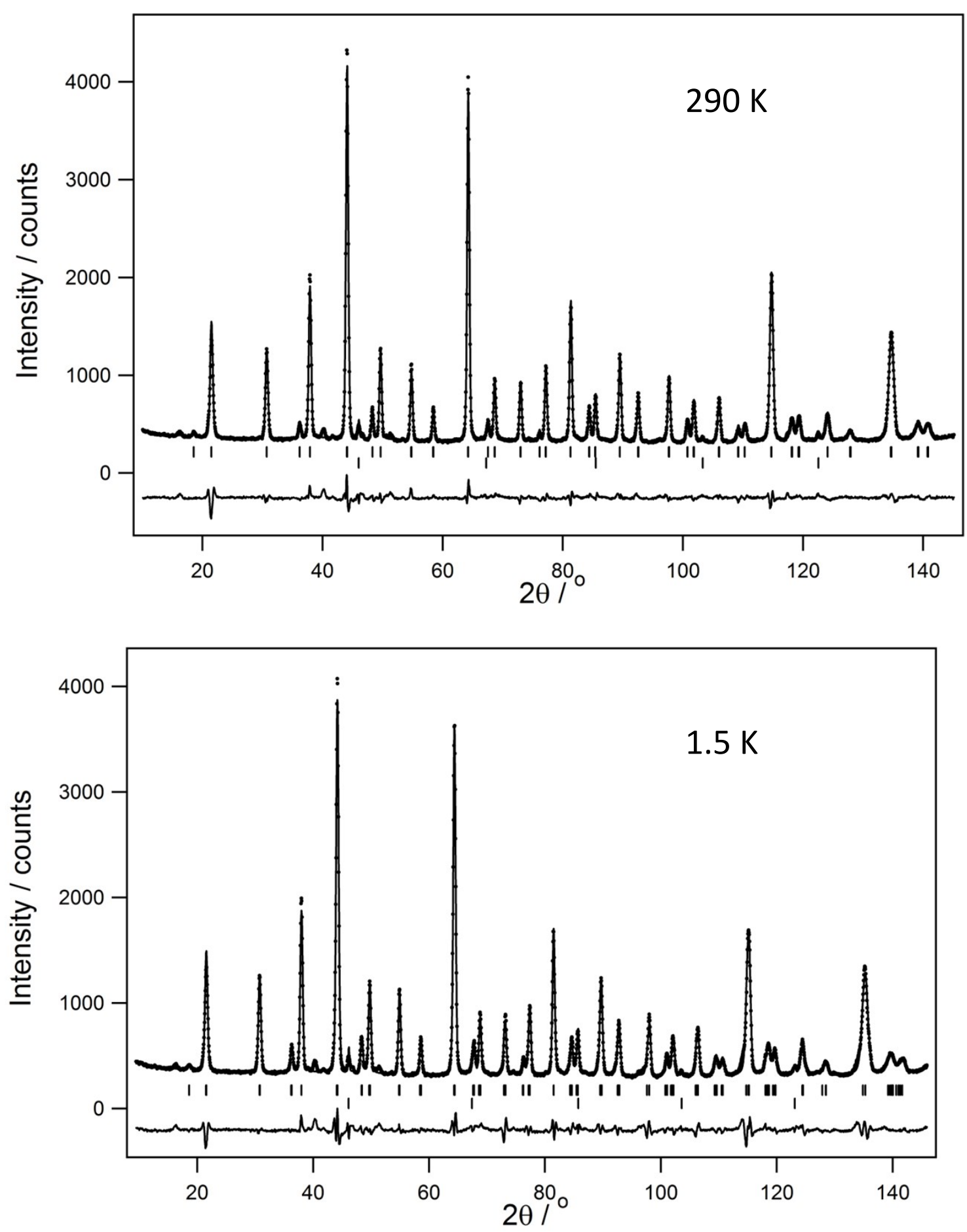

Figure S2 Neutron diffraction profiles collected at room temperature and $1.5 \mathrm{~K}$ from Ba${ }_{2} \mathrm{Nd}_{0.75} \mathrm{Fe}_{0.25} \mathrm{MoO}_{6}$. Experimental and calculated profiles are shown as points and lines respectively. The vertical markers indicate the positions of allowed Bragg reflections from the tetragonal perovskite (upper marks) and the iron impurity (lower marks). The quality of fit is indicated by the parameters $R_{w p}=3.90, X^{2}=6.94$ for $290 \mathrm{~K}$ and $R_{w p}=$ $5.14, X^{2}=12.07$ for the data collected at $1.5 \mathrm{~K}$. 

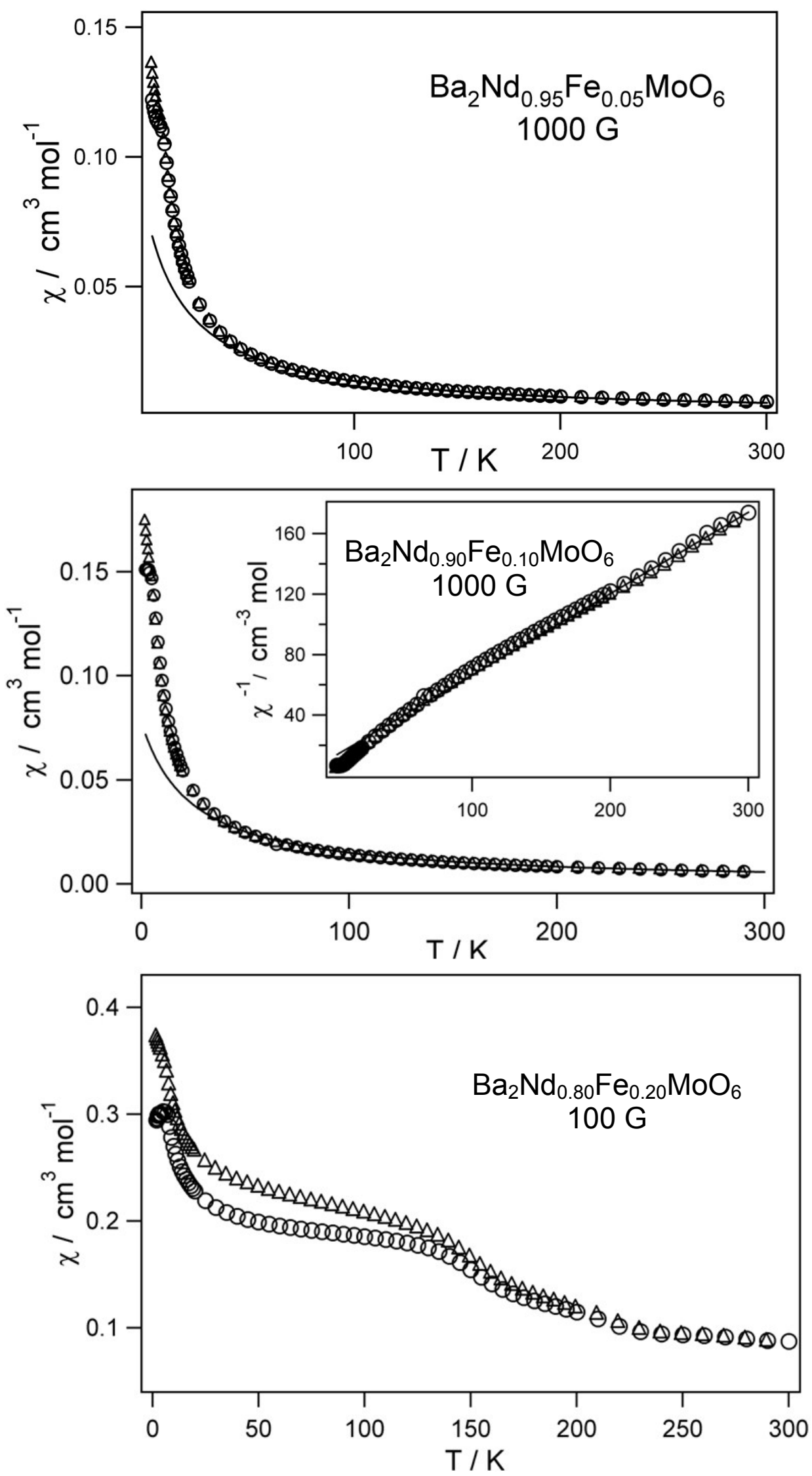

Figure S3 Magnetic susceptibility data collected from (top) $\mathrm{Ba}_{2} \mathrm{Nd}_{0.95} \mathrm{Fe}_{0.05} \mathrm{MoO}_{6}$ in $1000 \mathrm{G}$ field, (middle) $\mathrm{Ba}_{2} \mathrm{Nd}_{0.90} \mathrm{Fe}_{0.10} \mathrm{MoO}_{6}$ in $1000 \mathrm{G}$ field and (bottom) $\mathrm{Ba}_{2} \mathrm{Nd}_{0.80} \mathrm{Fe}_{0.20} \mathrm{MoO}_{6}$ in $100 \mathrm{G}$ field. Data are were collected after cooling in either zero applied magnetic field (circles) or after cooling in the measuring field cooled (triangles). The inset shows the Curie Weiss fit to the inverse susceptibility. 


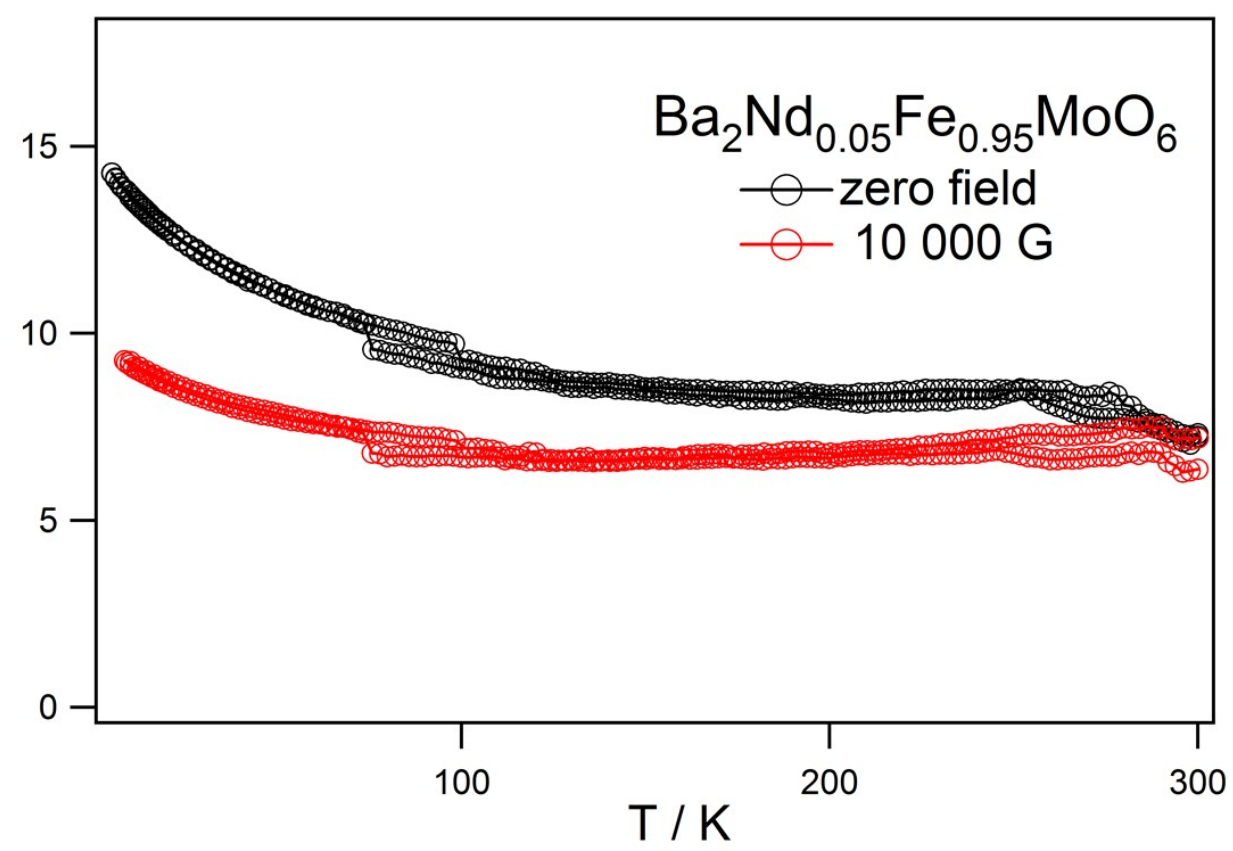

Figure S4 The temperature dependence of the resistivity of $\mathrm{Ba}_{2} \mathrm{Nd}_{0.05} \mathrm{Fe}_{0.95} \mathrm{MoO}_{6}$ as a function of applied magnetic field. Data collected in zero applied field and $10000 \mathrm{G}$ are represented as black and red circles respectively. 


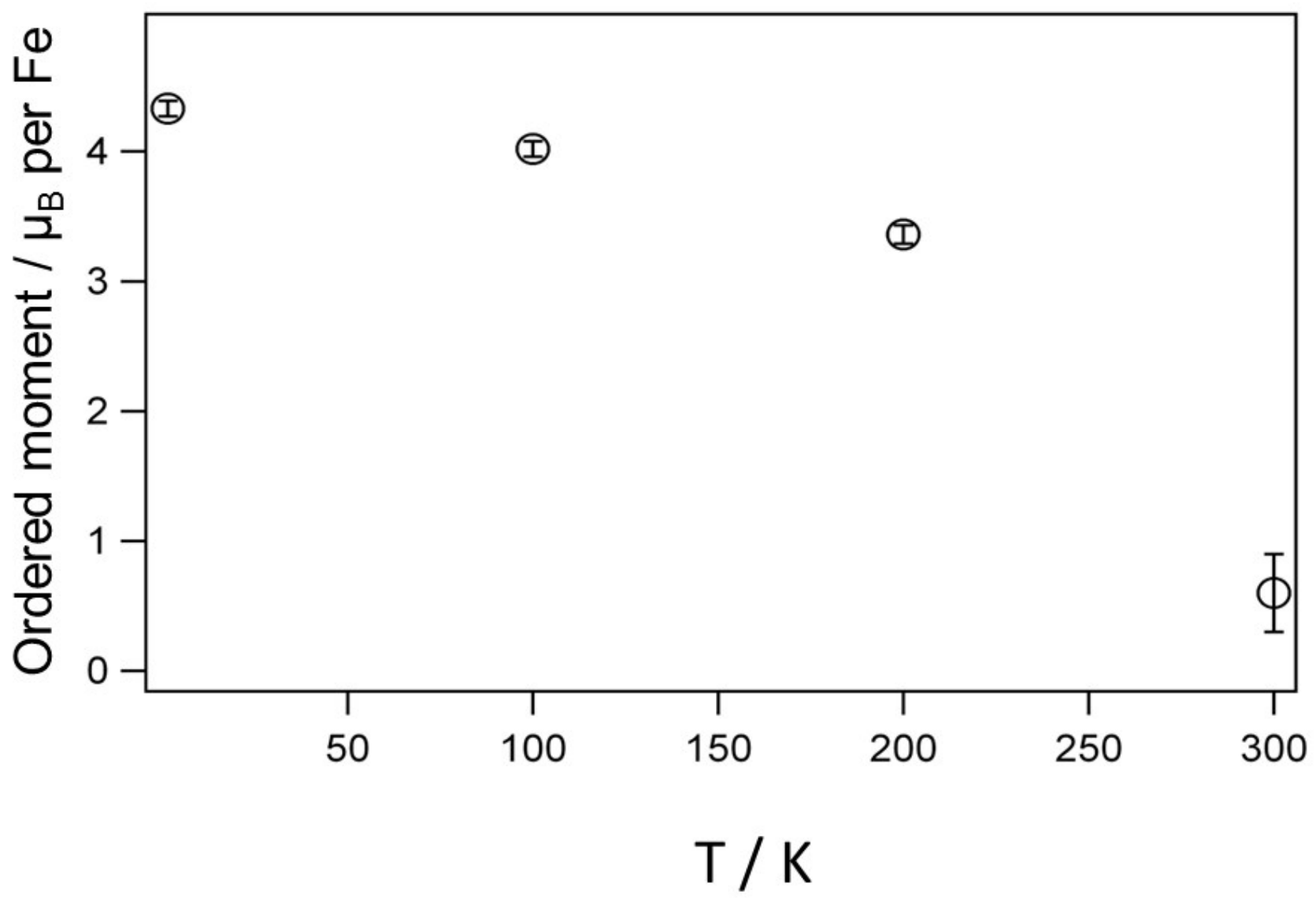

Figure S5 The long-range ordered magnetic moment in $\mathrm{Ba}_{2} \mathrm{Nd}_{0.95} \mathrm{Fe}_{0.05} \mathrm{MoO}_{6}$ derived from fitting neutron diffraction data collected at various temperatures between $1.5 \mathrm{~K}$ and room temperature. The error bars indicate one standard deviation in the Rietveld refinement. 